\title{
Abordagem hidroeconômica como subsídio à tomada de decisão na alocação de água em reservatório do semiárido brasileiro
}

\author{
Hydro-economic approach as a subsidy to making decisions \\ in the water allocation in brazilian semi-arid reservoir
}

\begin{abstract}
Emanoella Rodrigues Ribeiro de Oliveira ${ }^{1}$ (D), Andrea Sousa Fontes ${ }^{2}$ (D), Raymundo José Santos Garrido ${ }^{1}$ (D), William Dantas Vichete ${ }^{3}$ (D), Yvonilde Dantas Pinto Medeiros ${ }^{1}$ (D), Paulo Romero Guimarães Serrano de Andrade² (D)

${ }^{1}$ Universidade Federal da Bahia - UFBA, Salvador, BA, Brasil. E-mails: emanoella.rodrigues@outlook.com, raymundojosegarrido@gmail.com, yvonilde.medeiros@gmail.com

2Universidade Federal do Recôncavo da Bahia - UFRB, Cruz das Almas, BA, Brasil. E-mail: andreafontes@ufrb.edu.br, prserrano@yahoo.com.br

${ }^{3}$ Universidade de São Paulo - USP, São Paulo, SP, Brasil. E-mail: vichete@gmail.com
\end{abstract}

\begin{abstract}
Como citar: Oliveira, E. R. R., Fontes, A. S., Garrido, R. J. S., Vichete, W. D., Medeiros, Y. D. P., \& Andrade, P. R. G. S. (2021). Abordagem hidroeconômica como subsídio à tomada de decisão na alocação de água em reservatório do semiárido brasileiro. Revista de Gestão de Água da América Latina, 18, e23. https://doi.org/10.21168/rega.v18e23
\end{abstract}

RESUMO: A integração entre ferramentas hidrológicas e econômicas na alocação de água, através da abordagem hidroeconômica, reflete à percepção de escassez desse recurso. Diante disso, o presente artigo tem como objetivo estabelecer procedimentos para a implementação da abordagem hidroeconômica na alocação de água em reservatórios do semiárido brasileiro que apresentam conflitos de uso envolvendo a irrigação, utilizando uma aplicação no reservatório Mirorós, localizado nas bacias hidrográficas dos rios Verde e Jacaré/BA. A metodologia contemplou a determinação do comportamento das demandas de água dos três principais usuários do reservatório e a análise da abordagem hidroeconômica no processo de alocação de água, utilizando o modelo de suporte à decisão AcquaNet. Com base na análise econômica identificou-se que o abastecimento humano apresentou menor valor agregado à água, e que a minimização dos custos econômicos ocorreu quando maior quantidade de água foi alocada para a irrigação. Como os benefícios adquiridos por determinados usuários podem impor elevados custos aos demais, os resultados revelaram que a análise hidroeconômica influi no processo de alocação de água. Diante dos resultados obtidos, fundamentou-se a proposta de um modelo de alocação de água que associa a alocação negociada e a abordagem hidroeconômica.

Palavras-chave: Alocação de Água; Modelo Hidroeconômico; Custo de Escassez; Operação de Reservatórios.

\begin{abstract}
The integration between hydrological and economic tools in the allocation of water, through the hydroeconomic approach, reflects the perception of scarcity of this resource. In view of this fact, the present work aims at establishing procedures for an economic approach implementation when allocating capacity of water reservoirs in the Brazilian semiarid region which present conflicts and disputes regarding irrigation, using an application was made in the Mirorós reservoir, located in the Verde and Jacaré River Basin/BA. The methodology included the determining the behavior of the water demands of the three main users of the reservoir and the analyzing the hydro-economic approach in the water allocation process, using the AcquaNet decision support model. Based on the economic analysis, it was identified that human supply has less added value to water, and that the minimization of economic costs occurred when more water was allocated to the downstream irrigators. As the benefits acquired by certain users can impose high costs on others, the results revealed that the hydro-economic analysis influences the water allocation process. In face of the results during the three stages, the proposal for a water allocation model that combines the negotiated allocation and the hydro-economic approach.
\end{abstract}

Keywords: Water Allocation; Hydro-Economic Model; Scarcity Cost; Reservoir Operation.

\section{INTRODUÇÃO}

A tomada de decisão na região semiárida representa um grande desafio para a gestão sustentável dos recursos hídricos. Alcançar a sustentabilidade na gestão dos recursos hídricos é alocar a água para atender as demandas das gerações presentes de forma que não prejudique a capacidade de regeneração 
dos sistemas hídricos, e não comprometa o atendimento das necessidades de futuras gerações (Agência Nacional de Águas, 2017a; Silva et al., 2017). Sendo assim, é preciso compreender que a água é um recurso natural limitado e que deve ser alocada de forma sustentável.

Uma das limitações da alocação de água é a não maximização do potencial dos recursos hídricos. Em sistemas hídricos em que a água se torna um fator limitante para o desenvolvimento econômico, é importante maximizar os benefícios econômicos, porém isso exigirá a utilização de abordagens mais sofisticadas no processo de alocação de água. Caso contrário, a alocação da água dificilmente será eficiente, e não existirá mecanismos que garantam a racionalidade do uso, em termos sociais, econômicos ou ambientais, o que pode gerar aumento dos conflitos entre os usos (Organização para a Cooperação e o Desenvolvimento Econômico, 2015).

Na alocação de água, as decisões de um usuário afetam o uso da água por outros usuários, causando um efeito externo, denominado externalidade. As decisões individuais de cada usuário não levam em consideração esse efeito. No entanto, os instrumentos econômicos funcionam como mecanismos de internalização das externalidades que um usuário impõe aos demais (Carrera-Fernandez \& Garrido, 2002). A abordagem econômica auxilia gestores de recursos hídricos a tratar a água com uma visão que reflete a escassez, assim a demanda hídrica deixa de ser um requerimento "fixo" e passa a ser variável, representada pelo valor econômico (Moraes et al., 2018; Harou et al., 2009). A demanda variável de água é de particular interesse para a economia, visto que a demanda de água em quantidades variáveis revela a noção de preço, tema central aos problemas de natureza econômica. Dessa forma, o não atendimento ou atendimento parcial das demandas de águas dos usuários incorrem em custos de escassez, ou seja, custos econômicos associados à escassez hídrica. Vichete \& Mello Júnior (2021) ressaltam que os custos de escassez são aliados ao desenvolvimento de regulamentações e regras operacionais durante períodos de escassez. Silva \& Moraes (2018) ressaltam que as regras operacionais dos reservatórios e as restrições institucionais, como por exemplo a prioridade de uso para o consumo humano, oferecem grande impacto econômico nos usos da água.

Diante disso, além das restrições ambientais, como a disponibilidade hídrica, a alocação de água deve considerar os aspectos econômicos relacionados ao seu uso ou escassez, sendo necessário realizar uma análise conjunta de modelos econômicos e modelos ambientais (Dalcin \& Marques, 2019). Sendo assim, autores incorporaram os valores econômicos da água no processo de alocação e gerenciamento dos recursos hídricos, resultando na análise hidroeconômica. Os estudos relacionados a modelos hidroeconômicos têm avançado nas últimas décadas, possibilitando a integração das análises hidrológicas, ambientais e econômicas.

Os modelos hidroeconômicos permitem a análise das restrições físicas do sistema hídrico e da complexidade das decisões econômicas dos usuários (MacEwan et al., 2017). Esses modelos representam, em uma escala regional, os aspectos hidrológicos, ambientais, econômicos e de engenharia em escala regional, sendo que a alocação de água é avaliada pelos valores econômicos que esse recurso gera (Harou et al., 2009). Em outras palavras, a modelagem hidroeconômica é guiada pela maximização dos benefícios econômicos, mas sujeita às restrições hidrológicas e às regras de operação do sistema. Trata-se, pois, de um problema de otimização condicionada.

Considerar que o valor econômico e os custos de obtenção da água variam com a quantidade demandada é o conceito chave para promover a eficiência da alocação da água. Esse conceito é representado pela curva de demanda, que apresenta a variação do preço que o usuário está disposto a pagar a partir da quantidade de água. Sendo assim, as curvas de demanda da água são ferramentas que permitem integrar o comportamento econômico em modelos matemáticos que avaliam o efeito econômico das diferentes políticas de gestão de recursos hídricos, tais como o preço da água (Harou et al., 2009; Moraes et al., 2018).

No entanto, incorporar o preço da água na gestão de recursos hídricos não é uma tarefa simples. Embora a escassez configure o valor econômico à água, o fato de esse recurso não ser precificado através de fatores mercadológicos apresenta como consequência a carência de dados estatísticos que possibilitem o estabelecimento de um valor por metro cúbico o qual os usuários estariam dispostos a pagar. Os valores e custos de escassez são, então, desconhecidos (Carrera-Fernandez \& Garrido, 2002; Mattiuzi et al., 2020).

A identificação do preço da água requer a determinação da alocação economicamente ideal, ou seja, a alocação de água no ponto de eficiência econômica, atendendo princípio de equimarginalidade discutido na microeconomia. A modelagem hidroeconômica é capaz de induzir mudanças no comportamento dos usuários. Sendo assim, os modelos hidroeconômicos podem subsidiar a criação de instrumentos de gestão que induzam a alocações economicamente mais eficientes (Silva \& Moraes, 2021; Moraes et al., 2014). 
Nesse contexto, o objetivo geral do presente artigo é estabelecer procedimentos para a implementação da abordagem hidroeconômica como subsídio à tomada de decisão na alocação de água em reservatórios do semiárido brasileiro que apresentam conflitos de uso envolvendo a irrigação.

\section{ÁREA DE ESTUDO}

O reservatório Mirorós (Manoel Novais) é formado pelo barramento do rio Verde, e localiza-se no extremo sudoeste da Região de Planejamento e Gestão das Águas (RPGA) dos rios Verde e Jacaré, no perímetro pertencente aos municípios Gentio de Ouro/BA e Ibipeba/BA, sendo suas coordenadas

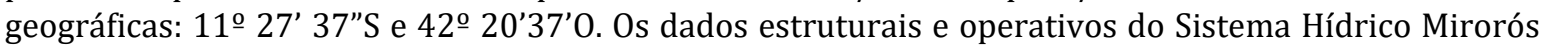
são apresentados na Tabela 1.

Tabela 1 - Dados operacionais do Sistema Hídrico Mirorós

\begin{tabular}{ccc|c|c|c}
\hline $\begin{array}{c}\text { Área de } \\
\text { drenagem } \\
\left(\mathbf{k m}^{2}\right)\end{array}$ & $\begin{array}{c}\text { Volume } \\
\text { máximo } \\
\left(\mathbf{h m}^{3}\right)\end{array}$ & $\begin{array}{c}\text { Volume } \\
\text { mínimo } \\
\left(\mathbf{h m}^{3}\right)\end{array}$ & $\begin{array}{c}\text { Volume } \\
\text { Útil } \\
\left(\mathbf{h m}^{3}\right)\end{array}$ & $\begin{array}{c}\text { NA máximo } \\
\text { operacional } \\
(\mathbf{m})\end{array}$ & $\begin{array}{c}\text { NA mínimo } \\
\text { operacional } \\
(\mathbf{m})\end{array}$ \\
\hline $1.774,70$ & $158,40^{1} / 166,92^{2}$ & 20,12 & 138,29 & 532,00 & 502,00 \\
\hline
\end{tabular}

Fonte: Próprio autor com base em Agência Nacional de Águas (2017a). Notas: ${ }^{1}$ Valor referenciado em ANA, 2017a; ${ }^{2}$ Valor referenciado em ANA, 2017b.

A Figura 1 apresenta as médias mensais das vazões afluentes ao reservatório disponibilizadas pela Coordenação de Estudos Hidrológicos (COHID) da Agência Nacional de Águas (ANA). Com base nesses dados, observa-se que o período seco compreende os meses de maio a outubro, apresentando valores de vazões quase nulos, e sendo mais críticos os meses de junho a agosto. Maiores vazões ocorrem nos meses de novembro a março, destacando-se o mês de dezembro.

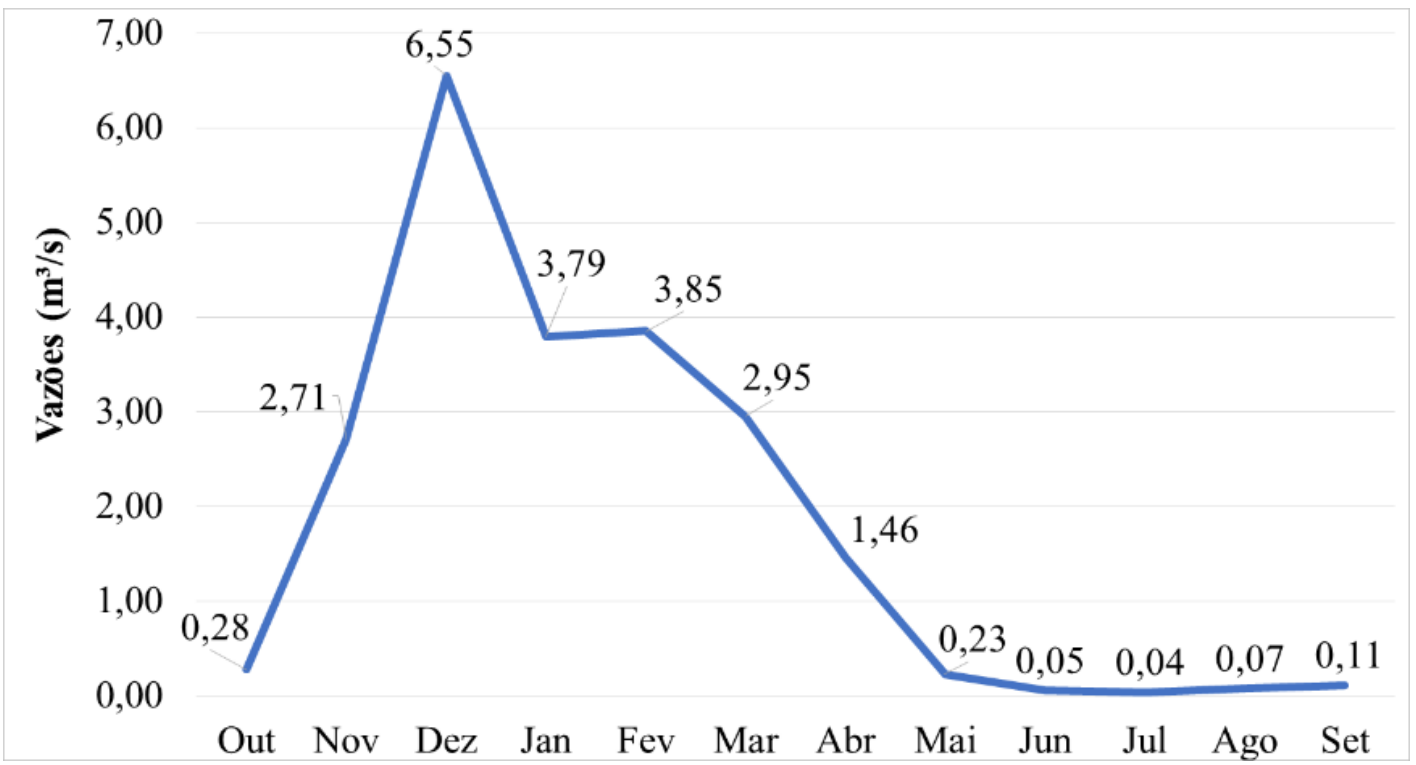

Figura 1 - Vazões médias mensais afluentes ao reservatório Mirorós (1913 - 2013). Fonte: Próprio autor com base em Agência Nacional de Águas (2020a).

A Figura 2 apresenta a variação do volume de água no reservatório entre 1990 e 2020 disponibilizados no Sistema de Acompanhamento de Reservatórios (SAR) (Agência Nacional de Águas, 2020a). É possível observar períodos de redução do volume de água do reservatório ao longo dos anos. Entre os anos de 2012 e 2015, o reservatório permaneceu com um volume de 5\% a 12\% da sua capacidade máxima. Em 2016, registrou-se um aumento no volume do reservatório, chegando a atingir $26 \%$ da sua capacidade total, no entanto o reservatório voltou a sofrer com a redução do volume, chegando a cair para aproximadamente $4 \%$ da sua capacidade máxima volumétrica no ano de 2018, o 
que manteve a cota do nível da água em 495,04. A partir de abril de 2020 o reservatório passou a receber recarga de água significativa, aumentando seu volume para quase $18 \%$ da sua capacidade.

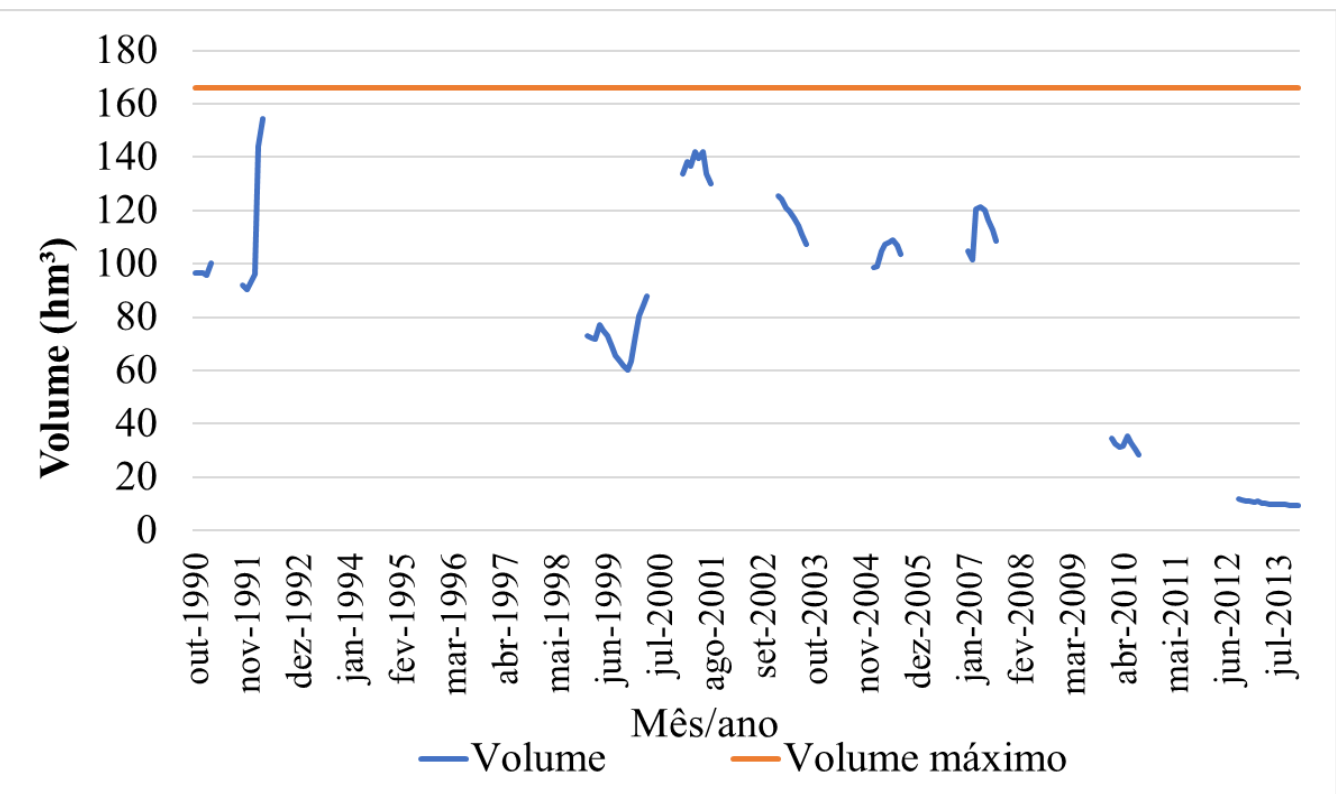

Figura 2 - Volume de Água no Reservatório Mirorós (1990 - 2020). Fonte: Próprio autor com base em Agência Nacional de Águas (2020a).

Na Figura 2, os dados de 1990 a 2012 são dados referentes às medições da cota do reservatório, disponibilizados pela Coordenação de Estudos Hidrológicos da ANA, e dados de 2012 a 2020 estão disponíveis em SAR/ANA, 2020. No histórico de volumes, observa-se ainda que o período apresenta diversas falhas de medições, por exemplo, entre 1992 e 1998 não é possível estimar o comportamento do reservatório, o mesmo acontecendo com outros períodos menores, tais como 2008 a 2010 e 2010 a 2012. Os dados passam a ser mais consistentes a partir do mês de outubro de 2012. De acordo com a Agência Nacional de Águas (2017b), o volume do reservatório permaneceu abaixo de 38\% da sua capacidade total em $50 \%$ do tempo, e nunca houve ocorrência de vertimento.

Em relação às demandas, os principais usos da água no Reservatório Mirorós são: a Adutora do Feijão responsável pela captação da água do reservatório para o abastecimento urbano de 15 municípios, sendo operada pela Empresa Baiana de Água e Saneamento (Embasa); o Perímetro Irrigado Mirorós, que possui área irrigável de mais de 2.000 ha e é operado pela Codevasf; e usos a jusante da barragem, que envolvem principalmente irrigantes ribeirinhos no rio Verde.

Através dos dados hidrológicos do reservatório, fica evidente que o mesmo apresenta grandes períodos de escassez, impossibilitando o atendimento de todas as demandas outorgadas. Os conflitos surgem entre dois usos distintos (abastecimento humano e irrigação) e ainda dentro do próprio uso da irrigação (perímetro irrigado e irrigantes ribeirinhos do rio Verde) (Agência Nacional de Águas, 2017b).

Devido à contínua diminuição dos níveis no reservatório de Mirorós, o Sistema Integrado de Abastecimento de Água (SIAA) inaugurou uma nova captação de água, em fevereiro de 2013, em um braço rio São Francisco, no território do município de Xique-Xique/BA. Após a captação, a água é aduzida até a Estação de Tratamento de Água no município de Itaguaçu da Bahia/BA. Inicialmente, a adutora atendia aos municípios de América Dourada, Central, Irecê, João Dourado, Jussara, São Gabriel e Itaguaçu da Bahia. Posteriormente, a captação de água pela adutora do São Francisco foi ampliada, passando a abastecer os outros nove municípios interligados ao sistema, totalizando em 16 municípios abastecidos pela Adutora do rio São Francisco (Bahia, 2016; Agência Reguladora de Saneamento Básico do Estado da Bahia, 2016).

Mesmo após a construção da adutora do rio São Francisco, diminuindo a pressão hídrica sobre o reservatório, os conflitos persistem, visto que, ainda assim, a Embasa detém a outorga de captação de água no reservatório de aproximadamente 280 l/s. A outorga de captação no rio São Francisco corresponde a 657 l/s autorizada através da Resolução ANA no 1.235/2018, o que seria suficiente para atender a toda a demanda do abastecimento humano. Em 2016, a Embasa apresentou à ANA algumas justificativas em relação às outorgas de captação no rio São Francisco e no reservatório de Mirorós, entre 
elas foi citado que o sistema adutor do rio São Francisco foi projetado considerando-se a manutenção da vazão de 250 l/s para a adutora do Feijão. A ANA propôs o uso do açude Mirorós para abastecimento humano como manancial suplementar, e o rio São Francisco como manancial principal, possibilitando a flexibilização das prioridades de uso do reservatório (Agência Nacional de Águas, 2017b). Sendo assim, atualmente a captação para abastecimento humano é quase que totalmente realizada no rio São Francisco. No entanto, os termos de alocação de água ressaltam que a Embasa possui autorização prévia para utilizar eventualmente vazões maiores que as alocadas no açude, em caso de colapso no sistema adutor do rio São Francisco. Ressalta-se que esse colapso nunca ocorreu, porém, durante reunião de alocação de água em outubro de 2020, o gerente e representante da Embasa, relatou que, devido à escassez hídrica no reservatório Mirorós, a adutora do rio São Francisco atualmente encontra-se em operação cerca de 24 horas por dia, o que dificulta a realização de manutenções corretivas, justificando que haveria um maior conforto no sistema caso houvesse maior disponibilidade de água no reservatório Rocha (2020).

\section{MATERIAIS E MÉTODOS}

A fim de atingir os objetivos desse trabalho, a metodologia foi dividida nas seguintes etapas:

- $\quad$ análise do comportamento da demanda dos usuários do reservatório, visando determinar a curva de benefício marginal de cada usuário e identificar as informações necessárias para valoração da água nos usos de abastecimento humano e irrigação; e

- $\quad$ análise da influência da abordagem hidroeconômica na alocação de água, buscando identificar a relevância de utilizar a análise econômica como parte do processo de alocação de água e os procedimentos para sua implementação.

0 modelo de suporte à decisão escolhido para a simulação da operação do reservatório foi o AcquaNet, por ser um software de livre acesso e apresentar praticidade na construção de modelos e simulação dos sistemas hídricos. Após a modelagem, foram calculados os índices de desempenho do reservatório e os custos de escassez de cada alternativa de alocação, a fim de auxiliar à análise comparativa dos resultados.

Para realizar a modelagem hidroeconômica no AcquaNet, é necessário a inserção das curvas de demanda dos usuários da água, que foram estimadas utilizando o método de expansão do ponto, com base no modelo de equação exponencial requisitado pelo AcquaNet. As elasticidades-preço da demanda dos usuários utilizadas na construção das curvas de demanda foram obtidas através do método "tudo ou nada".

\section{Coleta e análise de dados}

a) Características físicas e operacionais do reservatório

As características físicas e operacionais do reservatório envolvem a curva cota-área-volume (CAV) e os volumes operacionais do reservatório, obtidos a partir do Marco Regulatório da Alocação de água no Mirorós (Agência Nacional de Águas, 2017b).

b) Vazões afluentes ao reservatório

A Coordenação de Estudos Hidrológicos (COHID) da Superintendência de Planejamento de Recursos Hídricos (SPR) da ANA disponibilizou os dados das vazões mensais afluentes ao reservatório Mirorós de 1913 a 2013 determinadas via modelagem chuva-vazão no âmbito do estudo "Reservatórios do Semiárido Brasileiro: hidrologia, balanço hídrico e operação". Observou-se que os dados de vazões de anos mais recentes representam grandes entradas de água no reservatório, o que corresponde à ausência de conflitos entre os usos, e que não representa a realidade atual do sistema.

Dessa forma, a fim de obter dados mais recentes e que melhor se adequem à realidade, optou-se por realizar o balanço hídrico mensal do reservatório, sendo a variável dependente o volume afluente $\left(V_{\mathrm{af}}\right)$, e assim obter dados de vazões afluentes a serem inseridos no AcquaNet, como mostram as equações a seguir. Ressalta-se que, como nunca houve vertimento no reservatório, não foi considerada a variável volume vertido no cálculo.

$V_{a f}=V_{f}+V E^{*} A+V_{c a p}-V_{i}-V P^{*} A$

As variáveis são descritas no Quadro 1. 
Quadro 1 - Referência dos dados utilizados pra o balanço hídrico mensal

\begin{tabular}{|c|l|l|}
\hline \multicolumn{2}{|l|}{ Variáveis } & \multicolumn{1}{c|}{ Referência } \\
\hline$V_{i}$ & $\begin{array}{l}\text { Volume inicial do } \\
\text { reservatório }\end{array}$ & SAR/ANA (Agência Nacional de Águas, 2020a) \\
\hline$V_{f}$ & Volume final do reservatório & SAR/ANA (Agência Nacional de Águas, 2020a) \\
\hline$V E$ & Vetor Evaporação & Agência Nacional de Águas (2017a) \\
\hline$V P$ & Vetor Precipitação & Agência Nacional de Águas (2017a) \\
\hline$A$ & Área alagada & $\begin{array}{l}\text { COHID, ANA (Agência Nacional de Águas, 2020b) e SAR/ANA } \\
\text { (Agência Nacional de Águas, 2020a) }\end{array}$ \\
\hline$V_{\text {cap }}$ & $\begin{array}{l}\text { Volume captado no } \\
\text { reservatório }\end{array}$ & $\begin{array}{l}\text { Boletins de acompanhamento da alocação - ANA (2015 a 2020) e } \\
\text { Distrito de Irrigação do Perímetro Irrigado de Mirorós (2019) }\end{array}$ \\
\hline
\end{tabular}

Fonte: Próprio autor (2020).

Observa-se que os dados volumes de água captados no reservatório não representam todo o período estudado (2013 a 2020). Dessa forma, foi necessário adotar algumas estratégias para compor os volumes captados no Balanço Hídrico. As falhas presentes nesses dados diminuem a confiabilidade na obtenção das vazões afluentes através do balanço hídrico do reservatório, porém não impedem que sejam utilizados na avaliação da metodologia de implementação da abordagem hidroeconômica na alocação de água.

Devido às dificuldades encontradas na obtenção das vazões afluentes pelo balanço hídrico, decidiu-se ainda realizar a modelagem com as vazões afluentes mensais geradas pela ANA, contendo o pior biênio de vazões (1931-1932). Ressalta-se que esse período é utilizado pela ANA para definir os estados hidrológicos e os cenários de alocações de água. A escolha do pior biênio é justificada em função da baixa capacidade de recuperação do reservatório, e devido aos resultados das vazões permanentes mensais com garantias de $90 \%$ e 95\%, que apresentaram valores nulos. Dessa forma, escolheu-se o período de maio de 1926 a abril de 1933, para fins de comparação dos resultados. Para tanto, as vazões foram realocadas temporalmente para o período de 2013 a 2020.

As vazões estimadas para o período de 2013-2020 (Figura 3a) apresentaram baixa disponibilidade hídrica, com vazão média do período igual a $0,71 \mathrm{~m}^{3} / \mathrm{s}$ e vazão máxima de $11,67 \mathrm{~m}^{3} / \mathrm{s}$. Observam-se, nesse período, estiagens mais prolongadas e poucos picos de vazão. Enquanto o período de vazões geradas pela ANA de 1926 a 1933 (Figura 3b) possui disponibilidade hídrica melhor, com anos secos intercalados com anos chuvosos, e mais ao final da série, um período seco mais prolongado. A vazão máxima desse período foi de $20,21 \mathrm{~m}^{3} / \mathrm{s}$ e vazão média igual a $1,10 \mathrm{~m}^{3} / \mathrm{s}$. Ainda assim, esse período apresenta criticidade nas demandas, observando diversos meses com vazões nulas.
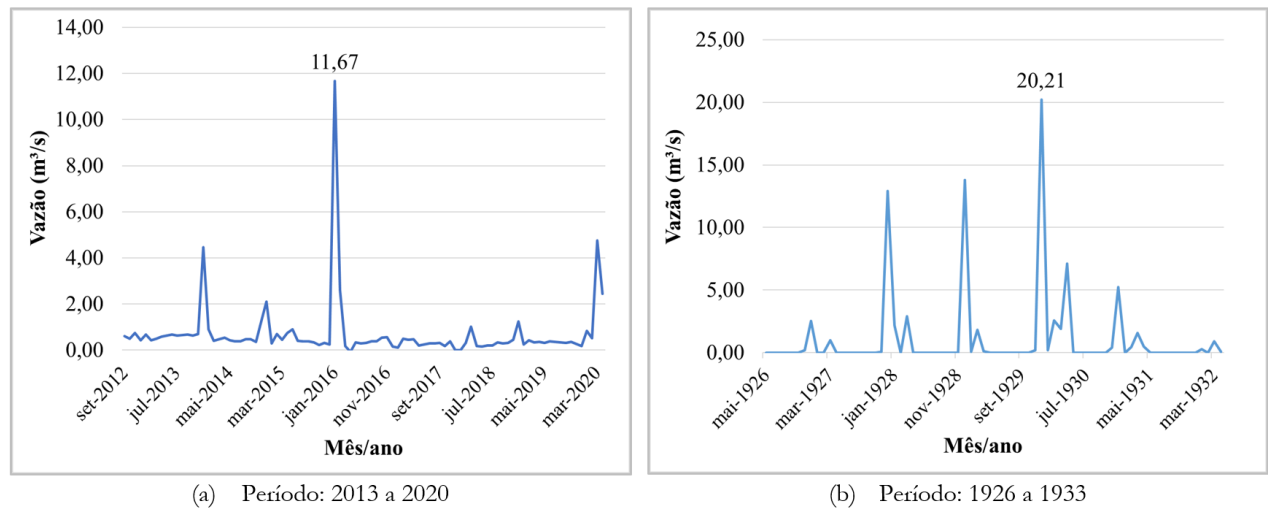

Figura 3 - Vazões médias mensais afluentes ao reservatório. Fonte: Próprio autor com base em Agência Nacional de Águas (2020a, 2020b).

\section{c) Evaporação e Precipitação}

O vetor evaporação utilizado no estudo foi apresentado pela Agência Nacional de Águas (2017a), sendo obtido através da interpolação de dados de evaporação total de estações cadastradas nas Normais Climatológicas do Brasil (1961-1990) do Instituto Nacional de Meteorologia (INMET). Enquanto o vetor precipitação utilizado, também elaborado pela Agência Nacional de Águas (2017a), foi obtido através da 
interpolação de dados da precipitação acumulada (INMET) e dos postos pluviométricos (HidroWeb). Os vetores são apresentados na Tabela 2.

Tabela 2 - Evaporação mensal (mm) no reservatório Mirorós

\begin{tabular}{c|c|c|c|c|c|c|c|c|c|c|c|c|c}
\hline Mês & \multicolumn{1}{c}{ Jan } & \multicolumn{1}{c}{ Fev } & Mar & Abr & Mai & Jun & Jul & Ago & Set & Out & Nov & Dez \\
\hline $\begin{array}{c}\text { Evaporação } \\
\text { (mm) }\end{array}$ & 165 & 147 & 150 & 147 & 167 & 189 & 228 & 276 & 293 & 289 & 233 & 178 \\
\hline $\begin{array}{c}\text { Precipitação } \\
\text { (mm) }\end{array}$ & 94 & 82 & 95 & 43 & 7 & 2 & 2 & 1 & 12 & 36 & 124 & 132 \\
\hline
\end{tabular}

Fonte: Adaptado de Agência Nacional de Águas (2017b).

\section{d) Outorgas de uso da água}

De acordo com a Nota Técnica referente ao Marco Regulatório de Alocação de Água no sistema hídrico Mirorós (Agência Nacional de Águas, 2017b), os usos associados ao reservatório Mirorós e suas respectivas demandas médias anuais são apresentados no Quadro 2.

Quadro 2 - Usos associados ao reservatório e respectivas vazões médias anuais

\begin{tabular}{|c|c|c|c|}
\hline \multicolumn{2}{|c|}{ Usos associados ao reservatório } & $\begin{array}{l}\text { Demanda } \\
\text { média anual }\end{array}$ & Referência \\
\hline \multirow{2}{*}{$\begin{array}{l}\text { Usos outorgáveis } \\
\text { no reservatório }\end{array}$} & $\begin{array}{l}\text { Abastecimento público - SIAA rio Verde } \\
\text { (Irecê e região) - Adutora do Feijão }\end{array}$ & 458 & Resolução ANA no 274/2010 \\
\hline & $\begin{array}{l}\text { Irrigação no Perímetro } \\
\text { Mirorós }\end{array}$ & 871 & Declaração CNARH nำ273062 \\
\hline $\begin{array}{l}\text { Usos outorgáveis } \\
\text { a jusante }\end{array}$ & $\begin{array}{l}\text { Usos a jusante até a confluência com o } \\
\text { riacho da Conceição }\end{array}$ & 180 & \multirow{2}{*}{$\begin{array}{l}\text { Estimativa COMAR com base } \\
\text { na NT INEMA no } 34 / 2016 \text { e no } \\
\text { histórico de defluência do } \\
\text { reservatório }\end{array}$} \\
\hline $\begin{array}{l}\text { Perenização do } \\
\text { rio Verde }\end{array}$ & $\begin{array}{l}\text { Perenização do rio Verde até a } \\
\text { confluência com o Riacho Santana }\end{array}$ & 70 & \\
\hline \multicolumn{2}{|r|}{ Total } & 1.579 & - \\
\hline
\end{tabular}

Fonte: Adaptado de Agência Nacional de Águas (2017b).

Ressalta-se que a vazão média anual da captação de água do reservatório para a Embasa refere-se à outorga anterior, sendo que, atualmente, a vazão média anual foi reduzida para 278 l/s, devido à captação de água no rio São Francisco. Atualmente a Embasa possui outorga de 657 l/s no rio São Francisco para abastecimento do SIAA de Irecê através da Resolução no 1.235/2018, publicada em 22/08/2018 e válida até 22/08/2028, de acordo com Agência Nacional de Águas (2020b). Foram utilizados ainda dados de outorga de uso da água a jusante do reservatório Mirorós obtidos junto à entidade reguladora estadual, o Instituto do Meio Ambiente e Recursos Hídricos (2019). Observa-se que o Marco Regulatório estima a demanda de $180 \mathrm{~L} / \mathrm{s}$ para usos outorgáveis a jusante, no entanto, os dados fornecidos pelo Instituto do Meio Ambiente e Recursos Hídricos (2019) apresentam a vazão anual outorgada de $112 \mathrm{~L} / \mathrm{s}$ para irrigação a jusante do reservatório até a confluência com o riacho da Conceição.

\section{Determinação das curvas de demanda}

A função de demanda pela água mede os benefícios marginais associados à variação da quantidade do recurso, sendo assim, para estimar a função é necessário obter dados relacionados à quantidade total do recurso, e os benefícios e custos econômicos associados (Silva et al., 2015). 0 benefício marginal é o preço obtido na curva de demanda e também pode ser chamado de receita marginal ou utilidade marginal.

No AcquaNet, utiliza-se a curva de benefício marginal (curva de demanda) na forma de uma função exponencial decrescente, do tipo:

$\boldsymbol{P}=\boldsymbol{a} \times \boldsymbol{e}^{-\boldsymbol{b} \times \boldsymbol{Q}}$ 
Onde 'P' é o benefício marginal em $\$ /\left(\mathrm{m}^{3} / \mathrm{s}\right)$, 'Q' é a vazão em $\mathrm{m}^{3} / \mathrm{s}$ e 'a' e 'b' são coeficientes da curva exponencial.

Os coeficientes podem ser facilmente obtidos a partir de dois pontos conhecidos da curva de demanda $\left(\mathrm{P}_{1}, \mathrm{Q}_{1}\right.$ e $\left.\mathrm{P}_{2}, \mathrm{Q}_{2}\right)$. Quando não se têm dois pontos conhecidos na função, mas se conhece um ponto $\left(\mathrm{P}_{1}, \mathrm{Q}_{1}\right)$ e a elasticidade-preço da demanda $(\epsilon)$ também é possível obter os coeficientes 'a' e 'b'. Dessa forma, as curvas de demanda são definidas por::

$$
\boldsymbol{a}=\frac{\boldsymbol{P}_{1}}{\exp \frac{\boldsymbol{\operatorname { l n }}\left[\frac{\boldsymbol{P}_{1}}{\boldsymbol{P}_{2}}\right]}{1-\frac{\boldsymbol{Q}_{2}}{\boldsymbol{Q}_{1}}}}=\frac{\boldsymbol{P}_{1}}{\exp \left[\frac{1}{\epsilon}\right]}
$$

$\boldsymbol{b}=\frac{\boldsymbol{\operatorname { n }}\left[\frac{\boldsymbol{P}_{1}}{\boldsymbol{P}_{2}}\right]}{\boldsymbol{Q}_{2}-\boldsymbol{Q}_{1}}=\frac{-1}{\in \times \boldsymbol{Q}}$

Onde ' $\mathrm{P}_{1}$ ' e ' $\mathrm{P}_{2}$ ' representam o benefício marginal em $\mathrm{R} \$ /\left(\mathrm{m}^{3} / \mathrm{s}\right)$ nos pontos 1 e 2 , respectivamente; ' $\mathrm{Q}_{1}$ ' e ' $\mathrm{Q}_{2}$ ' são as vazões em $\mathrm{m}^{3} / \mathrm{s}$ nos pontos $1 \mathrm{e} 2$, respectivamente; $\mathrm{e} \in$ representa a elasticidade-preço da demanda

Na metodologia utilizada determina-se a curva de demanda de cada usuário a partir da expansão de um ponto conhecido, método denominado de expansão do ponto. A grande limitação desse método está relacionada à utilização da elasticidade como um valor constante, podendo ocasionar super ou subestimação do valor da água em pontos distantes do ponto de operação utilizado como base para a estimativa da curva.

No Quadro 3 são apresentados as equações e os dados utilizados para estimativa dos benefícios anuais dos usuários.

Quadro 3 - Dados utilizados na análise hidroeconômica

\begin{tabular}{|c|c|c|c|c|}
\hline Usuário & Equação & Dados & Valor & Unidade \\
\hline \multirow{3}{*}{$\begin{array}{c}\text { Abastecimento } \\
\text { Humano }\end{array}$} & \multirow{3}{*}{$\begin{array}{c}P_{1}= \\
\sum_{i}^{M} \frac{\left(T M A_{i}-D E F_{i}\right) P_{i} p_{i}}{P o p T o t}\end{array}$} & População & $\begin{array}{c}297.221(15 \\
\text { municípios) } \\
303.050(16 \\
\text { municípios) }{ }^{1} \\
\end{array}$ & hab \\
\hline & & Tarifa de água & 4,531 & $\mathrm{R} \$ / \mathrm{m}^{3}$ \\
\hline & & $\begin{array}{c}\text { Despesa de } \\
\text { exploração por } \mathrm{m}^{3} \\
\text { faturado }\end{array}$ & $4,40^{1}$ & $\mathrm{R} \$ / \mathrm{m}^{3}$ \\
\hline \multirow{5}{*}{ Perímetro Irrigado } & \multirow{5}{*}{$\begin{array}{c}P_{1}= \\
\left(\text { Prod }^{*} \text { Preço-CM }\right) * A C \\
\text { Vcap }_{\text {Mirorós }}+\text { Vcap poços }\end{array}$} & Produtividade & $16.882,50^{2}$ & $\mathrm{~kg} / \mathrm{ha}$ \\
\hline & & Preço médio & $1,38^{2}$ & $\mathrm{R} \$ / \mathrm{kg}$ \\
\hline & & Custos & $14.085,34^{2}$ & $\mathrm{R} \$ / \mathrm{ha}$ \\
\hline & & Área cultivada & 732,372 & hectares \\
\hline & & $\begin{array}{l}\text { Volume de água } \\
\text { captado }\end{array}$ & $11.277 .306,00^{3}$ & $\mathrm{~m}^{3} / \mathrm{ano}$ \\
\hline \multirow{5}{*}{ Irrigantes a jusante } & \multirow{5}{*}{$P_{1}=\frac{\frac{(V P-V D)}{A C} * A I}{Q_{\text {out }}}$} & Vazão outorgada & $112^{4}$ & $\mathrm{~L} / \mathrm{s}$ \\
\hline & & Área irrigada & 212,64 & hectares \\
\hline & & Valor de produção & $52.520 .00,00^{5}$ & $\mathrm{R} \$ /$ ano \\
\hline & & $\begin{array}{c}\text { Área destinada à } \\
\text { colheita }\end{array}$ & 7.6645 & hectares \\
\hline & & $\begin{array}{l}\text { Valor das despesas } \\
\text { dos } \\
\text { estabelecimentos } \\
\text { agropecuários }\end{array}$ & $38.082 .000,00^{6}$ & $\mathrm{R} \$ /$ ano \\
\hline
\end{tabular}

Fonte: Próprio autor (2021). Notas: ${ }^{1}$ Sistema Nacional de Informação sobre Saneamento (2018), ${ }^{2}$ Companhia de Desenvolvimento do Vale do São Francisco e do Parnaíba (2019), ${ }^{2}$ Distrito de Irrigação do Perímetro Irrigado de Mirorós (2019), ${ }^{4}$ Instituto do Meio Ambiente e Recursos Hídricos (2019), ${ }^{5}$ PAM/IBGE (Instituto Brasileiro de Geografia e Estatística, 2017b), ${ }^{6}$ Censo Agropecuário/IBGE (Instituto Brasileiro de Geografia e Estatística, 2017a) 


\section{Determinação da elasticidade-preço da demanda}

A sensibilidade da curva de demanda é mensurada através do conceito de elasticidade-preço da demanda. A elasticidade-preço da demanda mede a elasticidade, ou capacidade de resposta da demanda pela água frente a uma mudança em seu preço, sendo seu valor dado em percentual (Reynaud \& Romano; 2018). A elasticidade-preço da demanda pode ser escrita como:

$\in=\frac{\frac{\Delta w}{w}}{\frac{\Delta p}{p}}$

Onde: ' $\epsilon$ ' = elasticidade-preço da demanda (adimensional), ' $w^{\prime}=$ demanda $\left(\mathrm{m}^{3} / \mathrm{s}\right)$, ' $\Delta \mathrm{w}^{\prime}=$ variação da demanda $\left(\mathrm{m}^{3} / \mathrm{s}\right)$, ' $\mathrm{p}$ ' = preço do bem $(\mathrm{R} \$)$ e ' $\Delta \mathrm{p}^{\prime}$ = variação do preço $(\mathrm{R} \$)$.

Assim sendo, a elasticidade-preço da demanda mede a variação relativa na quantidade demandada para determinada variação relativa no preço.

No método da expansão do ponto, a elasticidade-preço da demanda deve ser obtida externamente ao método. Para oferecer maior confiabilidade ao estudo, esse parâmetro deve representar a área que estiver sendo estudada.

0 método adotado para estimar a elasticidade-preço demanda no presente trabalho foi a função de demanda "tudo ou nada" discutida em Carrera-Fernandez \& Garrido (2002) e Garrido (2018). A função de demanda "tudo ou nada” é obtida através de dois pares de pontos (preço e quantidade) que revelam o custo de oportunidade da água para cada usuário, também denominado preço de reserva. De acordo com Carrera-Fernandez \& Garrido (2002), o preço de reserva é o maior valor que o usuário estaria disposto a pagar e permanecer indiferente entre continuar utilizando a água do atual manancial ou buscar uma alternativa que lhe ofereça menor custo. Os autores ressaltam que o preço de reserva representa uma estimativa legítima do valor social da água.

Os preços de reserva de cada usuário são estimados a partir de uma situação hipotética em que se interrompe a oferta de água do manancial utilizado, e os usuários são forçados a buscarem soluções alternativas. Buscam-se então duas alternativas de menor custo, que representarão dois pontos da curva "tudo ou nada".

Existem diversas alternativas para substituição da fonte de água utilizada, sendo as mais procuradas: importação de água de outras bacias, captação de água subterrânea ou aquisição de água em carros-pipa (Garrido, 2018). Sendo assim, na obtenção da função da demanda "tudo ou nada”, foi necessário identificar dois pares ordenados (vazão e preço) para o uso do abastecimento humano e para o uso da irrigação. Dentre as possíveis alternativas para o uso do abastecimento humano, adotou-se a implantação de poços tubulares para captação de água subterrânea, e a implantação de uma adutora de água bruta transportando água do leito principal do rio São Francisco, no município de Xique-Xique, até o município de Irecê, onde concentra-se a maior parte da população atendida pelo SIAA.

Para os usuários da irrigação, a primeira alternativa foi a construção de uma adutora de água bruta com captação no leito principal do rio São Francisco (município de Xique-Xique), passando pelo município de Itaguaçu da Bahia e chegando até o perímetro irrigado de Mirorós, onde concentra-se a maior demanda de água para a irrigação; e a segunda alternativa adotada, já utilizada como captação complementar pelo Distrito de Irrigação do Perímetro Irrigado de Mororós (DIPIM), foi a captação de água subterrânea.

Admitiu-se que os custos de cada alternativa são a disposição a pagar do usuário, ou seja, os preços de reservas que compõem a curva "tudo ou nada". Ressalta-se que é importante considerar que tal estimativa de custos apresentam incertezas. Por exemplo, como citado por Fernandez y Fernandez et al. (2007), os valores das curvas de custos, que foram utilizadas para determinação dos custos de captação de água superficial, não substituem orçamentos específicos das obras. No entanto, definiu-se a metodologia adequada ao presente estudo, visto que o objetivo do mesmo não é avaliar a alocação de água na área de estudo, mas sim avaliar a implementação da abordagem hidroeconômica em processos de alocação de água.

Para a composição dos custos unitários, foram estimados os custos anuais de implantação (custo de implantação distribuído pelo tempo de vida útil da estrutura) e custos de operação e manutenção de cada alternativa de acordo com as referências apresentadas no Quadro 4. 
Quadro 4 - Referências utilizadas na obtenção dos custos de alternativas de captação de água

\begin{tabular}{|c|c|}
\hline Referência & Dados \\
\hline $\begin{array}{c}\text { Fernandez y Fernandez } \\
\text { et al. (2007) }\end{array}$ & $\begin{array}{c}\text { Preços de implantação, operação e manutenção de sistemas de adução e estações } \\
\text { de bombeamento. Vida útil das adutoras e estações de bombeamento }\end{array}$ \\
\hline $\begin{array}{c}\text { Agência Peixe Vivo } \\
(2018)\end{array}$ & Locação e nivelamento de adutora de água bruta \\
\hline $\begin{array}{c}\text { Companhia de Energia } \\
\text { Elétrica da Bahia (2020) }\end{array}$ & Tarifas de energia elétrica, sendo considerado o Consumo ativo Fora de Ponta \\
\hline $\begin{array}{c}\text { Companhia de } \\
\text { do } \begin{array}{c}\text { Convolvimento do Vale } \\
\text { Parnaíba (2013) }\end{array}\end{array}$ \\
\hline Tropical Poços (2020)
\end{tabular}

Fonte: Próprio autor (2021).

De posse dos custos unitários e demandas em cada alternativa, é possível ajustar a função linear da demanda "tudo ou nada", a partir dos coeficientes linear $(\alpha)$ e angular $(\beta)$, a partir das Equações 6 e 7.

$\boldsymbol{\alpha}=\frac{\left(p_{1} * q_{2}-p_{2} * q_{1}\right)}{\left(\boldsymbol{q}_{2}-\boldsymbol{q}_{1}\right)}$

$\boldsymbol{\beta}=\frac{\left(p_{2}-p_{1}\right)}{\left(\boldsymbol{q}_{2}-\boldsymbol{q}_{1}\right)}$

Onde ' $\mathrm{p}_{1}$ ' e ' $\mathrm{p}_{2}$ ' representam o custo unitário em $\mathrm{R} \$ / \mathrm{m}^{3}$ nas alternativas 1 e 2 , respectivamente; e ' $\mathrm{q}_{1}$ ' e ' $\mathrm{q}_{2}$ ' representam a vazão em $\mathrm{m}^{3} / \mathrm{s}$ nas alternativas 1 e 2 , respectivamente.

A partir dos coeficientes linear e angular é possível obter a função de demanda "tudo ou nada", a função de demanda ordinária, e por consequência, a elasticidade-preço da demanda, conforme mostra o Quadro 5.

Quadro 5 - Equações para a obtenção da elasticidade-preço da demanda na Função de Demanda “Tudo ou Nada”

\begin{tabular}{|c|c|}
\hline Função & Equação \\
\hline $\begin{array}{c}\text { Função de demanda “tudo ou nada" } \\
\text { (curva média de receita total) }\end{array}$ & $\boldsymbol{P}=\boldsymbol{\alpha}-\boldsymbol{\beta} q$ \\
\hline Curva da receita total & $R T=\alpha q-\beta q^{2}$ \\
\hline Função de demanda ordinária (curva de receita marginal) & $p=\frac{d R T}{d q}=\alpha-\beta q$ \\
\hline Parâmetro Elasticidade-preço da demanda & $\in=\frac{d q}{d p} * \frac{p}{q}=\frac{1}{\frac{d p}{d q}} * \frac{p}{q}=\frac{1}{\frac{d}{d q}(\alpha-\beta q)} * \frac{p}{q}$ \\
\hline
\end{tabular}

Fonte: Adaptado de Carrera-Fernandez \& Garrido (2002) e Garrido (2018).

\section{Aplicação da abordagem hidroeconômica}

Estimadas as curvas de demandas dos usuários da água, foi realizada uma análise da alocação de água através do ponto de vista econômico, utilizando o Módulo de Análise Econômica do LabSid AcquaNet (versão antiga). A modelagem dividiu-se em duas análises, como mostra a Figura 4. 


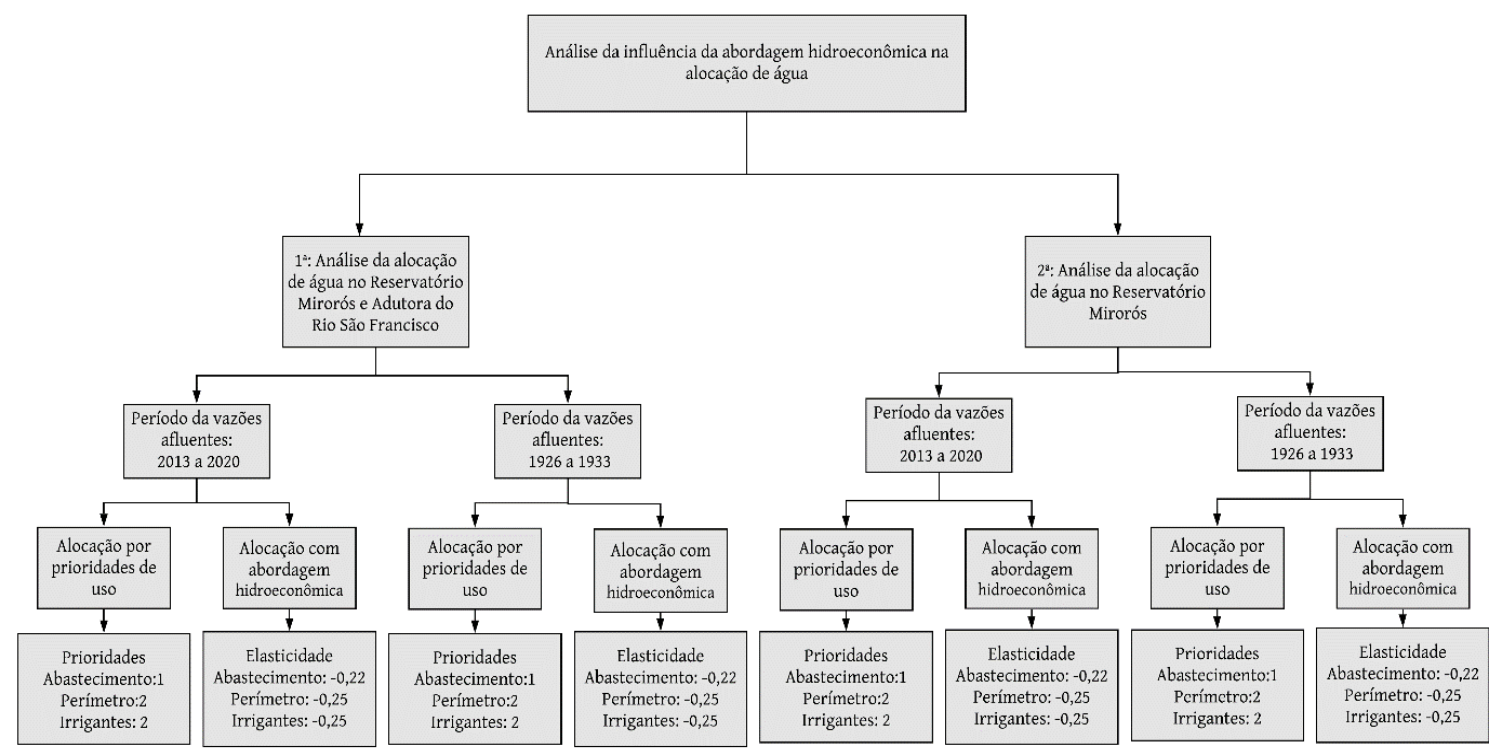

Figura 4 - Fluxograma da análise da influência da abordagem hidroeconômica na alocação de água. Fonte: Próprio autor (2020)

Na primeira análise, foi considerado o sistema hídrico formado pelo reservatório Mirorós e a adutora do rio São Francisco. Foi realizada uma análise comparativa entre dois períodos de vazões afluentes: um período de vazões geradas pelo próprio autor através do balanço hídrico do reservatório entre maio de 2013 e abril de 2020; e outro período de vazões afluentes geradas pela Agência Nacional de Águas no âmbito do Estudo dos Reservatórios do Semiárido Brasileiro entre maio de 1926 e abril de 1933.

A segunda análise assemelha-se à anterior, no entanto considerou-se o reservatório Mirorós isoladamente, ou seja, como se não houvesse o reforço da adutora do rio São Francisco. Essa análise foi utilizada a fim de entender o comportamento de reservatórios do semiárido que não possuem alternativas de abastecimento de água.

\section{Estimativa dos Benefícios econômicos e Custo de escassez}

Dentre os resultados obtidos com a simulação do sistema hídrico no AcquaNet, tem-se o Benefício Anual Médio de cada usuário. Esse dado está relacionado à vazão média de água fornecida e às curvas de benefício marginal. Ressalta-se que esses resultados são obtidos apenas em simulações realizadas com o Módulo de Análise Econômica, não sendo possível obter diretamente pelo modelo os benefícios econômicos das alternativas de alocação que utiliza o Módulo de Alocação de Água. Por isso, para fins comparativos, foi necessário realizar uma adaptação à simulação das alternativas no modelo com objetivo de estimar o benefício anual médio na alternativa de alocação de água por prioridade. Dessa forma, após a simulação das alternativas no módulo de alocação de água por prioridades, os resultados obtidos para vazões médias fornecidas de cada usuário, para cada mês de simulação, foram utilizados como vazão de demanda de seu respectivo usuário no módulo de análise econômica, que incorpora as curvas de benefício marginal.

Através dos valores de benefício econômico, é possível calcular o custo da escassez da água, um parâmetro econômico importante para analisar os impactos econômicos da alocação de água. Adotou-se a metodologia utilizada por Livele \& Silveira (2015), que estimaram o custo de escassez com o objetivo de avaliar os impactos econômicos da satisfação ou escassez hídrica de usuários agrícolas em diferentes cenários de disponibilidade hídrica.

A escassez de água representa a diferença entre a quantidade de água alocada e a quantidade demandada pelo usuário, ou seja, a quantidade que seria fornecida ao usuário em situações confortáveis de disponibilidade hídrica. Quando isso acontece o usuário usufrui de um benefício menor do que o benefício de ter sua demanda total atendida. 0 custo da escassez representa, então, o custo associado à quantidade de água que deixa de ser alocada para determinado usuário, sendo representada pela integral: 
$C_{\text {escassez }}=\int_{Q_{\text {aloc }}}^{Q_{d e m}} P(Q) d Q$

Onde: $\mathrm{C}_{\text {escassez }}=$ custo de escassez $(\mathrm{R} \$) ; \mathrm{Q}_{\mathrm{dem}}=$ vazão de demanda $\left(\mathrm{m}^{3} / \mathrm{s}\right), \mathrm{Q}_{\mathrm{aloc}}=$ vazão alocada $\left(\mathrm{m}^{3} / \mathrm{s}\right) ; \mathrm{e}$ $P(Q)$ é a curva de demanda, ou seja, a variação do preço (R\$) em função da vazão $\left(\mathrm{m}^{3} / \mathrm{s}\right)$.

Sabendo que a integral é a área sob uma curva, tem-se que o custo da escassez é a área sob a curva de demanda respeitando tais limites, e é dado em unidade monetária, como mostra a Figura 5.

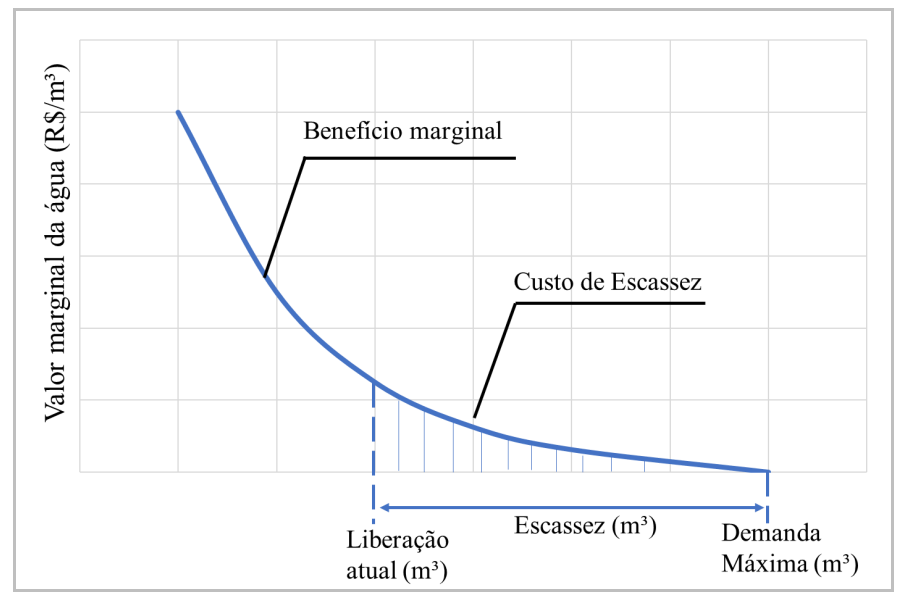

Figura 5 - Representação gráfica do custo da escassez. Fonte: Próprio autor (2021)

Ressalta-se que, no módulo de análise econômica do AcquaNet, a curva de benefício marginal é dividida em segmentos de retas, representados por arcos. 0 benefício econômico de cada arco é a área sob a reta. Dessa forma, obteve-se o custo de escassez médio anual das alternativas a partir da diferença entre o benefício anual médio ao atender $100 \%$ das demandas e o benefício anual médio no ponto da vazão alocada.

\section{Determinação dos Indicadores de desempenho}

O desempenho operacional de um sistema pode ser satisfatório ou insatisfatório. No caso de um reservatório, o desempenho está relacionado ao atendimento das demandas de uso da água. Hashimoto et al. (1982), consideraram o desempenho insatisfatório como uma falha. Sendo assim, a análise do desempenho do sistema hídrico, de acordo com o autor, concentra-se em um sistema de falhas. A falha é considerada como uma violação do padrão de desempenho.

O desempenho do sistema hídrico foi avaliado através dos seguintes indicadores de desempenho discutidos em Hashimoto et al. (1982); Loucks (1997); Basto et al. (2020); Preziosi et al. (2013):

- $\quad$ confiabilidade: representa a frequência ou probabilidade que ocorra um estado insatisfatório no sistema;

- resiliência: exprime em quanto tempo o reservatório irá se recuperar após a ocorrência de uma falha;

- $\quad$ vulnerabilidade: representa magnitude provável de uma falha, caso ela ocorra e;

- $\quad$ sustentabilidade: possibilita a quantificação da sustentabilidade de um sistema hídrico através de uma relação entre os indicadores acima [Sustentabilidade $=$ Confiabilidade $\mathrm{x}$ Resiliência $\mathrm{x}$ (1 - vulnerabilidade)]. 0 aumento da sustentabilidade de um sistema está relacionado ao aumento da confiabilidade e resiliência do mesmo, e à redução de sua vulnerabilidade. 


\section{RESULTADOS E DISCUSSÕES}

\section{Estimativa das elasticidades-preço da demanda}

Os custos de obtenção da água estimados nas alternativas para o abastecimento humano são apresentados na Tabela 3. Ressalta-se que o custo anual total é a soma do custo anual de implantação e dos custos anuais de operação e manutenção.

Tabela 3 - Custos das alternativas para o abastecimento humano

\begin{tabular}{|c|c|c|}
\hline Alternativa & Item & Preço \\
\hline \multirow{5}{*}{ Alternativa 1} & Custo Anual - Adutora de Água Bruta - Material Ferro Fundido - DN 600mm & $27.400 .169,19$ \\
\hline & Custo anual-Estação de Bombeamento - 2 estações com 1500 cv e 3600 cv & $17.067 .063,83$ \\
\hline & Custo anual total (R\$/ano) & $44.467 .233,01$ \\
\hline & Vazão anual média $\left(\mathrm{m}^{3} / \mathrm{s}\right)$ & 0,460 \\
\hline & Custo unitário $\left(\mathrm{R} \$ / \mathrm{m}^{3}\right)$ & 3,07 \\
\hline \multirow{5}{*}{ Alternativa 2} & Custo anual - Implantação de Poço tubular - Calcáreo & $1.258 .409,86$ \\
\hline & Custo anual - Adutora de Água Bruta - Material PVC- DN 100mm & $49.513 .172,87$ \\
\hline & Custo anual total (R $\$ / a n o)$ & $50.771 .582,73$ \\
\hline & Vazão anual média $\left(\mathrm{m}^{3} / \mathrm{s}\right)$ & 0,392 \\
\hline & Custo unitário $\left(\mathrm{R} \$ / \mathrm{m}^{3}\right)$ & 4,10 \\
\hline
\end{tabular}

Fonte: Próprio autor (2020).

Admitindo-se que os custos de cada alternativa correspondem à disposição a pagar do usuário, pode-se afirmar que o preço de reserva encontrado na alternativa 1 foi de $\mathrm{R} \$ 3,07 / \mathrm{m}^{3}$, sendo o primeiro par ordenado da função de demanda "tudo ou nada": $(0,460 ; 3,07)$. E o custo da alternativa 2 foi de $R \$ 4,10 / \mathrm{m}^{3}$, logo adotou-se como segundo par ordenado da função de demanda o ponto: $(0,392 ; 4,10)$. Tabela 4.

Os custos de obtenção da água estimados para as alternativas para a irrigação são apresentados na

Tabela 4 - Custos das alternativas para a irrigação

\begin{tabular}{l|c|c}
\hline \multicolumn{2}{c}{ Alternativa } & \multicolumn{2}{c}{ Item } & Preço \\
\hline \multirow{4}{*}{ Alternativa 1 } & Custo anual - Adutora de Água Bruta - Material Ferro Fundido - DN $800 \mathrm{~mm}$ & $34.934 .990,48$ \\
\cline { 2 - 3 } & Custo anual - Estação de Bombeamento - 2 estações com $1500 \mathrm{cv}$ e $3600 \mathrm{cv}$ & $24.104 .327,69$ \\
\cline { 2 - 3 } & Custo anual total $(\mathrm{R} \$ / \mathrm{ano})$ & $59.039 .318,17$ \\
\cline { 2 - 3 } & Volume anual de água demandada $\left(\mathrm{m}^{3} / \mathrm{ano}\right)$ & 0,983 \\
\cline { 2 - 3 } & Custo unitário $\left(\mathrm{R} \$ / \mathrm{m}^{3}\right)$ & $30.999 .888,00$ \\
\hline \multirow{4}{*}{ Alternativa 2 } & Custo anual - Poço tubular - Calcáreo & 1,90 \\
\cline { 2 - 3 } & Custo anual - Adutora de Água Bruta - Material PVC- DN $200 \mathrm{~mm}$ & $10.166 .249,30$ \\
\cline { 2 - 3 } & Custo anual total $(\mathrm{R} \$ / \mathrm{ano})$ & $11.034 .219,96$ \\
\cline { 2 - 3 } & Vazão média anual $\left(\mathrm{m}^{3} / \mathrm{s}\right)$ & 1,412 \\
\cline { 2 - 3 } & Volume anual de água demandada $\left(\mathrm{m}^{3} / \mathrm{ano}\right)$ & $44.528 .832,00$ \\
\cline { 2 - 3 } & Custo unitário $\left(\mathrm{R} \$ / \mathrm{m}^{3}\right)$ & 0,25 \\
\hline
\end{tabular}

Fonte: Próprio autor (2020).

0 custo da alternativa 1 foi de $\mathrm{R} \$ 1,90 / \mathrm{m}^{3}$. Dessa forma, admitiu-se que essa é a disposição a pagar dos usuários para uma vazão de $0,983 \mathrm{~m}^{3} / \mathrm{s}$. 0 primeiro par de pontos da função de demanda "tudo ou nada" da irrigação é: $(0,983 ; 1,90)$. Na alternativa 2 , obteve-se o custo unitário de $\mathrm{R} \$ 0,25 / \mathrm{m}^{3}$, sendo o segundo par de pontos da função linear igual a: $(1,412 ; 0,25)$.

Com base nos pares de pontos, obteve-se a função de demanda ordinária, e consequentemente a elasticidade-preço da demanda $(\epsilon)$ no ponto da demanda, como mostra o Quadro 6. 
Quadro 6 - Demandas por água das categorias de usuários do reservatório Mirorós e suas respectivas elasticidades-preços da demanda

\begin{tabular}{|c|c|c|c|c|}
\hline Uso & $\begin{array}{c}\text { Demanda “Tudo ou } \\
\text { Nada” }\end{array}$ & Receita Total & Demanda Ordinária & $|\epsilon|$ \\
\hline $\begin{array}{c}\text { Abastecimento } \\
\text { humano }\end{array}$ & $P=10,12-15,33 q$ & $R T=10,12 q-15,33 q$ & $p=10,12 q-30,67 q$ & 0,22 \\
\hline Irrigação & $P=5,70-3,86 q$ & $R T=5,70-3,86 q^{2}$ & $P=5,70-7,72 q$ & 0,25 \\
\hline
\end{tabular}

Fonte: Próprio autor (2020)

Os resultados encontrados nesse trabalho estão de acordo com a literatura, visto que a demanda da água, geralmente, é inelástica (valores absolutos entre 0 e 1). Isso porque a água é um bem dotado de grande valor para o usuário, pois não há um substituto direto e seu uso será necessário mesmo com grandes variações no preço. Carrera-Fernandez (1998) apud Carrera-Fernandez \& Garrido (2002) estimou para os usuários das bacias hidrográficas dos rios Verde e Jacaré as elasticidades-preço da demanda para o abastecimento humano e irrigação em -0,86 e - 0,17 , respectivamente. Observa-se que para os usuários da irrigação, os valores estimados nesse trabalho encontram-se próximos aos estimados pelo autor. No entanto, para o abastecimento humano ocorre uma variação. Ressalta-se que, a elasticidade-preço da demanda pode variar com diversos fatores variáveis ao longo do tempo, tais como a renda dos usuários e os custos das alternativas. Além disso, no presente estudo, considerou-se apenas os usuários do reservatório Mirorós, enquanto o autor estimou a elasticidade de todos os usuários das bacias hidrográficas dos rios Verde Jacaré.

\section{Estimativa das curvas de demanda de água dos usuários do reservatório Mirorós}

O primeiro resultado obtido foi o benefício líquido no ponto de operação dos usuários (Tabela 5).

Tabela 5 - Benefício marginal dos usuários do reservatório Mirorós

\begin{tabular}{c|c|c|c|c}
\hline Uso & $\begin{array}{c}\text { Abastecimento Humano } \\
\text { (15 municípios) }\end{array}$ & $\begin{array}{c}\text { Abastecimento Humano } \\
\text { (16 municípios) }\end{array}$ & $\begin{array}{c}\text { Perímetro } \\
\text { Irrigado }\end{array}$ & $\begin{array}{c}\text { Irrigantes a } \\
\text { jusante }\end{array}$ \\
\hline $\begin{array}{c}\text { Benefício marginal } \\
\left(\mathrm{R} \$ / \mathrm{m}^{3}\right)\end{array}$ & 0,283 & 0,294 & 0,600 & 0,418 \\
\hline
\end{tabular}

Fonte: Próprio autor (2020)

Os valores da água obtidos no ponto de operação foram maiores para o setor de irrigação do que para o setor de abastecimento humano, destacando-se ainda o Perímetro Irrigado de Mirorós. 0 valor da água para o abastecimento humano mais baixo foi consequência do valor do ganho líquido obtido pela companhia de abastecimento de água, que em alguns municípios foi negativo, mostrando uma baixa eficiência econômica.

Foi possível estimar que o benefício total obtido pelo usuário do abastecimento humano através da tarifação de água corresponde a $\mathrm{R} \$ 55.844 .964,40$, quando considerados os 16 municípios abastecidos pela companhia de saneamento. Enquanto o benefício obtido pela produção agrícola foi de R\$ 17.094.164,37 para o perímetro irrigado de Mirorós e R\$ 2.377.211,42 para os ribeirinhos a jusante do barramento. Observa-se que o valor obtido pelo usuário do abastecimento humano é muito maior do que pelos usuários da irrigação, no entanto as despesas da companhia de saneamento apresentaram valores elevados, gerando então um benefício líquido reduzido, o que acarretou em um valor da água no ponto de operação relativamente baixo, quando comparados aos demais usuários. 0 usuário do abastecimento humano pode melhorar o benefício líquido através de tecnologias e técnicas que visem a redução de perdas. Ressalta-se que o usuário da irrigação por ser um setor produtivo, com o objetivo de maximizar o lucro, apresenta maior rentabilidade.

As curvas de demanda da água estimadas para os três usuários, considerando os seus respectivos benefícios marginais e elasticidades-preço da demanda, são apresentadas na Figura 6. 


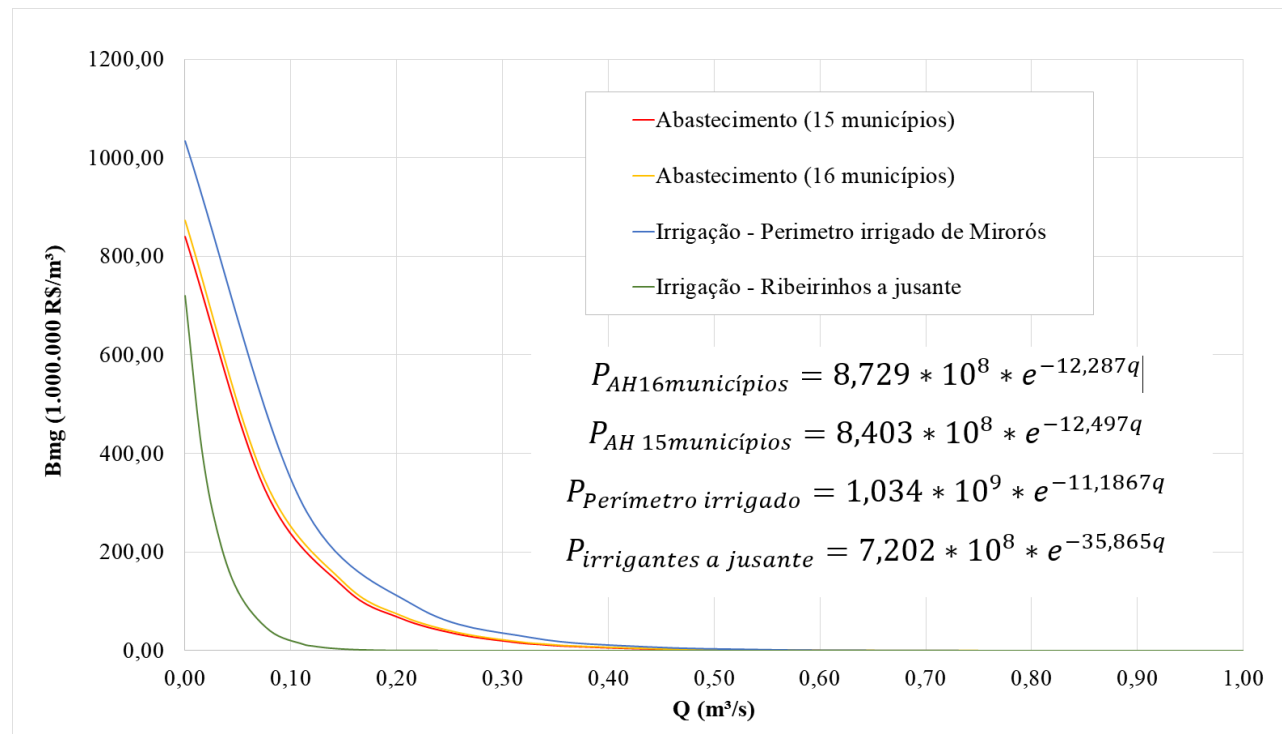

Figura 6 - Curva de Benefício marginal dos usuários do sistema hídrico Mirorós. Fonte: Próprio autor (2020)

\section{Análise da aplicação da abordagem hidroeconômica na alocação de água - Reservatório Mirorós e Adutora do rio São Francisco}

A primeira análise da modelagem hidroeconômica considerou o sistema hídrico formado pelo reservatório Mirorós e a adutora do rio São Francisco, sendo propostas quatro alternativas, que variaram de acordo com as vazões afluentes ao reservatório e ao tipo de alocação utilizado.

A Figura 7 apresenta os resultados obtidos da alocação entre os usuários nas alternativas de alocação considerando as vazões calculadas pelo próprio autor (2013-2020). Analisando as alternativas de alocação por prioridade (Alt P1) e alocação baseada na abordagem hidroeconômica (Alt E1), observa-se que a maximização do benefício econômico ocorre quando há maior atendimento às demandas dos usuários da irrigação, destacando-se os irrigantes a jusante do reservatório.

Considerando o período de vazões de 1926 a 1933 (Figura 8), observou-se que não houve alteração da vazão fornecida para o abastecimento humano entre as alternativas E2 e P2. Apenas os usuários da irrigação competiram pela oferta de água. Nesse período, houve a maximização do benefício econômico quando maior quantidade de água foi alocada para os irrigantes a jusante.

Ressalta-se que as duas séries históricas de vazões compreendem períodos críticos, embora os resultados tenham sido mais expressivos no período de vazões afluentes estimadas pelo autor (2013-2020), visto que houve maior déficit hídrico no sistema, evidenciando que quanto mais crítico o sistema maior foi a influência da abordagem hidroeconômica.

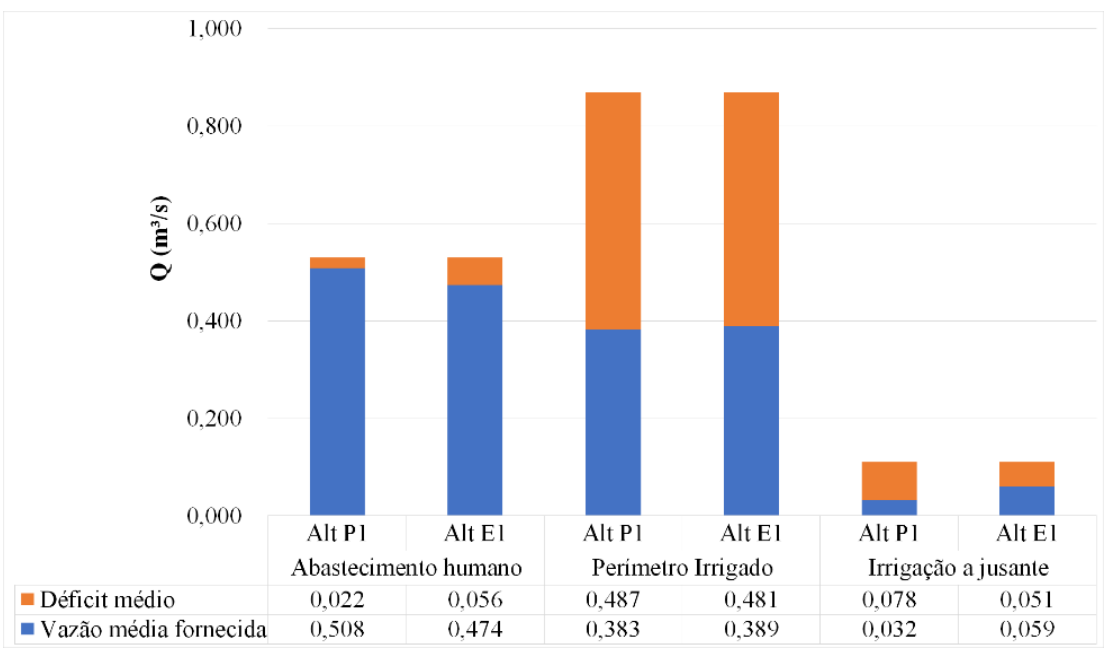

Figura 7 - Vazões fornecidas e déficit hídrico: reservatório Mirorós e adutora do rio São Francisco (2013-2020). Fonte: Próprio autor (2020). Nota: Alt P1 - Alocação por prioridade de uso, Alt E1 - abordagem hidroeconômica. 


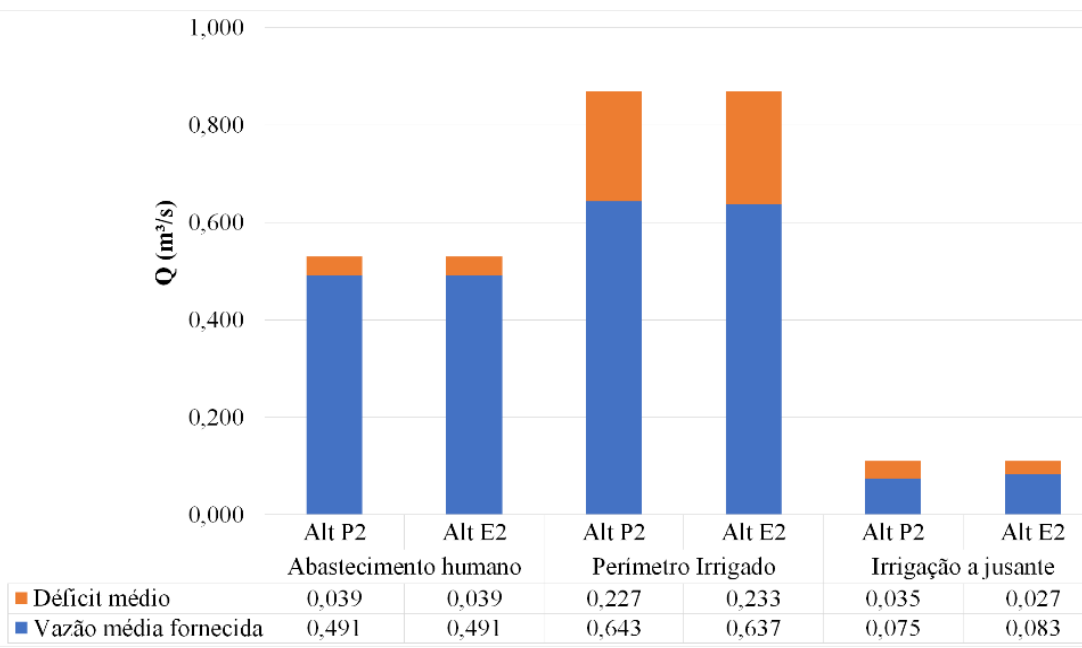

Figura 8 - Vazões fornecidas e déficit hídrico: reservatório Mirorós e adutora do rio São Francisco (1926-1933). Fonte: Próprio autor (2020). Nota: Alt P2 - Alocação por prioridade de uso, Alt E2 - abordagem hidroeconômica.

A Tabela 6 apresenta os indicadores de desempenho (confiabilidade, vulnerabilidade, resiliência e sustentabilidade) estimados para as alternativas abordadas.

Tabela 6 - Indicadores de desempenho da alocação de água no reservatório Mirorós e adutora do rio São Francisco

\begin{tabular}{|c|c|c|c|c|c|c|c|c|c|}
\hline \multirow{2}{*}{\multicolumn{2}{|c|}{$\begin{array}{l}\text { Indicador } \\
\text { Alternativa }\end{array}$}} & \multicolumn{2}{|c|}{ Confiabilidade } & \multicolumn{2}{|c|}{ Resiliência } & \multicolumn{2}{|c|}{ Vulnerabilidade } & \multicolumn{2}{|c|}{ Sustentabilidade } \\
\hline & & $\mathrm{P} 1$ & E1 & $\mathrm{P} 1$ & E1 & P1 & E1 & P1 & E1 \\
\hline \multirow{4}{*}{ Usuários } & Abastecimento Humano & $85 \%$ & $63 \%$ & $54 \%$ & $16 \%$ & $4 \%$ & $12 \%$ & $44 \%$ & $9 \%$ \\
\hline & Perímetro Irrigado & $30 \%$ & $30 \%$ & $8 \%$ & $8 \%$ & $56 \%$ & $54 \%$ & $1 \%$ & $1 \%$ \\
\hline & Irrigantes a jusante & $29 \%$ & $35 \%$ & $8 \%$ & $15 \%$ & $71 \%$ & $44 \%$ & $1 \%$ & $3 \%$ \\
\hline & Sistema 1 & $29 \%$ & $30 \%$ & $8 \%$ & $8 \%$ & $39 \%$ & $39 \%$ & $1 \%$ & $2 \%$ \\
\hline \multicolumn{2}{|r|}{ Alternativa } & $\mathrm{P} 2$ & E2 & $\mathrm{P} 2$ & E2 & $\mathrm{P} 2$ & E2 & $\mathrm{P} 2$ & E2 \\
\hline \multirow{4}{*}{ Usuários } & Abastecimento Humano & $83 \%$ & $83 \%$ & $21 \%$ & $21 \%$ & $7 \%$ & $7 \%$ & $17 \%$ & $17 \%$ \\
\hline & Perímetro Irrigado & $69 \%$ & $68 \%$ & $15 \%$ & $15 \%$ & $26 \%$ & $27 \%$ & $8 \%$ & $7 \%$ \\
\hline & Irrigantes a jusante & $68 \%$ & $75 \%$ & $15 \%$ & $24 \%$ & $32 \%$ & $25 \%$ & $7 \%$ & $13 \%$ \\
\hline & Sistema 1 & $68 \%$ & $68 \%$ & $15 \%$ & $15 \%$ & $20 \%$ & $20 \%$ & $8 \%$ & $8 \%$ \\
\hline
\end{tabular}

Fonte: Próprio Autor (2021). Nota: P1 - Alocação por prioridades de uso (2013-2021)/ E1 - Alocação hidroeconômica (2013-2021)/ P2 - Alocação por prioridades de uso (1926-1933)/ E2 - Alocação hidroeconômica (1926-1933)/ ${ }^{1}$ Sistema corresponde ao conjunto de demandas dos usuários.

Considerando o período de vazões afluentes 2013 a 2020 (Alternativas P1 e E1), é possível notar variações mais significativas no desempenho do atendimento dos usuários do abastecimento humano e irrigantes a jusante. 0 indicador de confiabilidade expressou um aumento no risco para a abastecimento humano quando se utiliza a abordagem hidroeconômica, e maior confiabilidade para os irrigantes a jusante. Em se tratando da capacidade de recuperação (resiliência) do sistema para atendimento às demandas, é possível notar períodos de falhas mais longos para atender ao abastecimento humano. Ocorre o oposto com o uso da água para a irrigação a jusante, apesar de ainda baixo, o indicador de resiliência sofre um aumento na abordagem hidroeconômica da alocação de água. No indicador de vulnerabilidade, destaca-se o uso da irrigação a jusante do reservatório, que apresentou melhorias significativas na vulnerabilidade, indicando que o atendimento a essa demanda apresenta falhas menos severas quando se incorpora a abordagem hidroeconômica. Verifica-se ainda que o usuário do abastecimento humano apresenta falhas mais severas na alternativa hidroeconômica, enquanto que, considerando o perímetro irrigado, ocorre pequena redução na vulnerabilidade do seu atendimento.

Com os indicadores citados, foi possível compreender a sustentabilidade do sistema no atendimento aos usos, observando valores muito baixos e nenhuma ou pouca variação para os usuários do perímetro irrigado e irrigação a jusante. Enquanto a sustentabilidade do atendimento às demandas de abastecimento humano apresentou uma grande redução na análise hidroeconômica, indicando assim maior risco para o abastecimento humano quando se considera a abordagem hidroeconômica.

Em se tratando do período de 1926 a 1933 (Alternativas P2 e E2), como observado nos resultados das vazões alocadas, os conflitos ocorrem principalmente entre as demandas do perímetro irrigado e dos 
usuários a jusante. Isso ficou evidenciado também nos resultados de desempenho do sistema hídrico. Nota-se que para o abastecimento humano, os indicadores de desempenho não apresentaram variações, comprovando que nesse período a abordagem hidroeconômica não influiu na alocação de água para o abastecimento humano. Pouca ou nenhuma variação dos indicadores também foi observada para o atendimento do perímetro irrigado. No entanto, ao analisar a irrigação a jusante, observam-se resultados mais expressivos. Quando incorporada a abordagem hidroeconômica na alocação, a demanda dos usuários irrigantes a jusante apresentou maior confiabilidade de atendimento, maior capacidade de recuperação após a ocorrência de falhas e redução da severidade das falhas.

Analisando os índices de desempenho do sistema, ou seja, avaliando todas as demandas em conjunto, não foram observadas alterações importantes ao incorporar a análise hidroeconômica. Podendo concluir que a análise dos indicadores de desempenho foi importante para avaliar o desempenho no atendimento por uso, e não do sistema hídrico em como um todo.

\section{Análise da aplicação da abordagem hidroeconômica na alocação de água - Reservatório Mirorós}

Considerando apenas o reservatório Mirorós como única forma de atendimento das demandas, ou seja, caso não houvesse o reforço da adutora do RSF, observam-se comportamentos similares aos resultados da análise anterior. As figuras a seguir, Figura 9 e Figura 10, apresentam as vazões alocadas e déficit hídrico para cada uso nos períodos de 2013 a 2020 e 1926 a 1933, respectivamente.

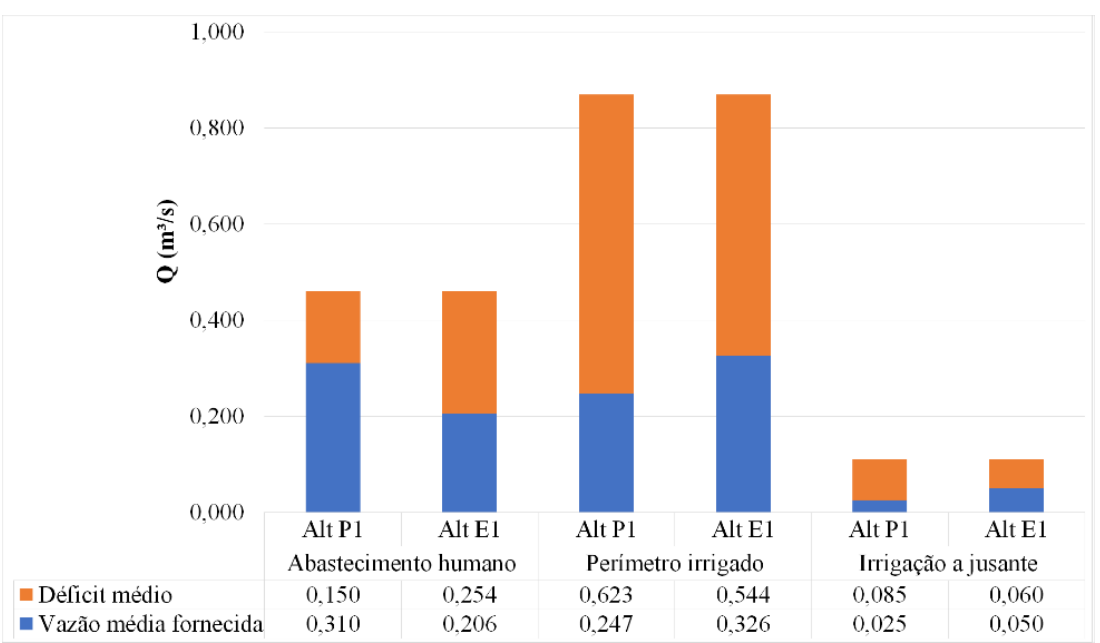

Figura 9 - Vazões fornecidas e déficit hídrico: Reservatório Mirorós (2013 - 2020). Fonte: Próprio autor (2020)

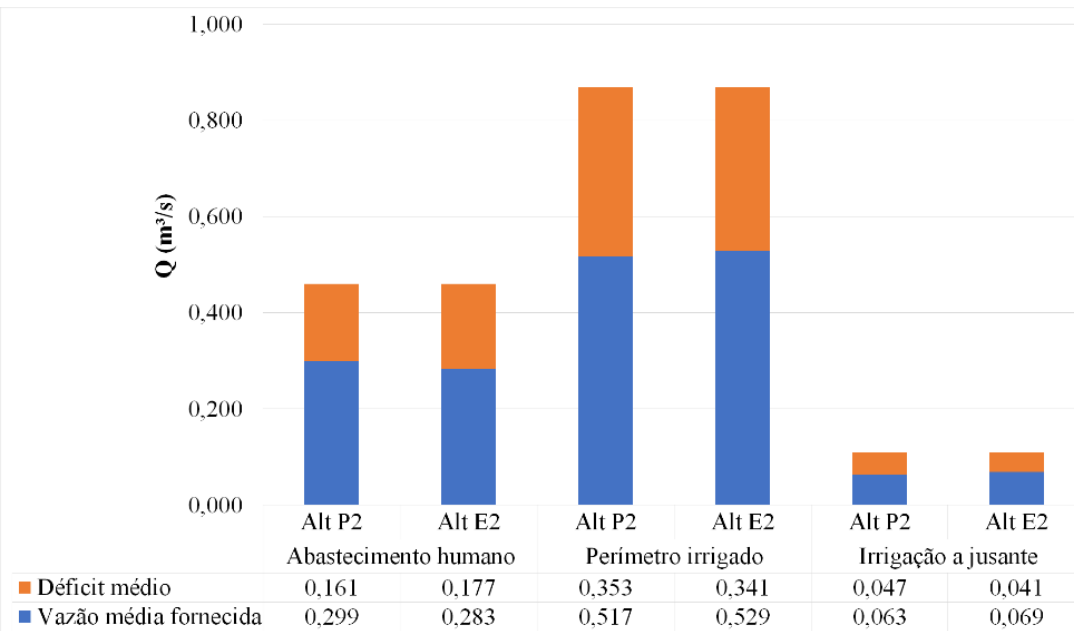

Figura 10 - Vazões fornecidas e déficit hídrico: Reservatório Mirorós (1926 - 1933). Fonte: Próprio autor (2020)

Como observado na primeira análise, quando a abordagem hidroeconômica foi inserida na alocação, ocorreu a redução das vazões fornecidas para o abastecimento humano e priorização do atendimento 
das demandas de irrigação. Dentre os usos de irrigação, destacou-se a demanda de água para a irrigação a jusante. Destaca-se ainda que o déficit médio para o abastecimento aumentou em quase 100\%, mostrando que esse usuário teve maiores prejuízos na presente análise do que na anterior, isso porque anteriormente a adutora do rio São Francisco atendia parte das suas demandas.

Quando se considerou apenas o reservatório Mirorós para atendimento das demandas, o uso do abastecimento humano apresentou maior déficit, e o oposto aconteceu com os usuários do perímetro irrigado e da irrigação a jusante.

Os índices de desempenho do reservatório são apresentados na Tabela 7.

Tabela 7 - Indicadores de desempenho da alocação de água no reservatório Mirorós

\begin{tabular}{|c|c|c|c|c|c|c|c|c|c|}
\hline \multirow{2}{*}{\multicolumn{2}{|c|}{$\begin{array}{l}\text { Indicador } \\
\text { Alternativa } \\
\end{array}$}} & \multicolumn{2}{|c|}{ Confiabilidade } & \multicolumn{2}{|c|}{ Resiliência } & \multicolumn{2}{|c|}{ Vulnerabilidade } & \multicolumn{2}{|c|}{ Sustentabilidade } \\
\hline & & P1 & E1 & $\mathrm{P} 1$ & E1 & $\mathrm{P} 1$ & E1 & $\mathrm{P} 1$ & E1 \\
\hline \multirow{4}{*}{ Usuários } & Abastecimento Humano & $42 \%$ & $26 \%$ & $12 \%$ & $8 \%$ & $33 \%$ & $55 \%$ & $3 \%$ & $1 \%$ \\
\hline & Perímetro Irrigado & $23 \%$ & $23 \%$ & $6 \%$ & $6 \%$ & $72 \%$ & $63 \%$ & $0,4 \%$ & $1 \%$ \\
\hline & Irrigantes a jusante & $23 \%$ & $29 \%$ & $6 \%$ & $12 \%$ & $77 \%$ & $54 \%$ & $0,3 \%$ & $2 \%$ \\
\hline & Sistema ${ }^{1}$ & $23 \%$ & $23 \%$ & $6 \%$ & $6 \%$ & $60 \%$ & $60 \%$ & $1 \%$ & $2 \%$ \\
\hline \multicolumn{2}{|r|}{ Alternativa } & $\mathrm{P} 2$ & E2 & $\mathrm{P} 2$ & E2 & $\mathrm{P} 2$ & E2 & $\mathrm{P} 2$ & E2 \\
\hline \multirow{4}{*}{ Usuários } & Abastecimento Humano & $63 \%$ & $57 \%$ & $29 \%$ & $17 \%$ & $35 \%$ & $39 \%$ & $12 \%$ & $6 \%$ \\
\hline & Perímetro Irrigado & $57 \%$ & $57 \%$ & $17 \%$ & $17 \%$ & $41 \%$ & $39 \%$ & $6 \%$ & $6 \%$ \\
\hline & Irrigantes a jusante & $57 \%$ & $61 \%$ & $17 \%$ & $24 \%$ & $43 \%$ & $37 \%$ & $5 \%$ & $9 \%$ \\
\hline & Sistema ${ }^{1}$ & $57 \%$ & $57 \%$ & $17 \%$ & $17 \%$ & $39 \%$ & $39 \%$ & $6 \%$ & $6 \%$ \\
\hline
\end{tabular}

Fonte: Próprio Autor (2021). Nota: P1 - Alocação por prioridades de uso (2013-2021)/ E1 - Alocação hidroeconômica (2013-2021)/ P2 - Alocação por prioridades de uso (1926-1927)/ E2 - Alocação hidroeconômica (1926-1927)/ ${ }^{1}$ Sistema corresponde ao conjunto de demandas dos usuários.

Considerando os indicadores de confiabilidade, resiliência e sustentabilidade do reservatório após a análise econômica, tem-se a redução desses indicadores para o abastecimento humano, e melhorias para a irrigação a jusante. Esses indicadores de desempenho não apresentaram variações para o perímetro irrigado de Mirorós.

Ao considerar o índice de vulnerabilidade, as falhas tornam-se menos severas para irrigação a jusante e para o perímetro irrigado quando a análise hidroeconômica é incorporada ao processo de alocação de água. Ocorre então o aumento da severidade das falhas no atendimento das demandas do abastecimento humano. Esse comportamento foi observado para os dois períodos de vazões afluentes estudados (2013-2020 e 1926-1933).

Os índices de sustentabilidade do reservatório (Tabela 7) apresentaram maiores variações para o atendimento ao abastecimento humano e aos irrigantes a jusante. Observa-se ainda que no período de 2013 a 2020, os resultados apresentados foram mais expressivos devido à maior criticidade do período, já citada anteriormente.

Ao comparar os resultados da primeira e segunda análises, observa-se que, mesmo o sistema não sendo capaz de atender todas as demandas na primeira análise, a adutora do rio São Francisco exerce um papel fundamental para aliviar a pressão sobre o reservatório Mirorós.

Enquanto a alocação por prioridades de usos tem como base a Política Nacional de Recursos Hídricos (abastecimento humano como uso prioritário em casos de escassez hídrica), a alocação utilizando a abordagem hidroeconômica ressalta a importância dos irrigantes a jusante para o desenvolvimento econômico.

Maiores desempenhos e benefícios econômicos são alcançados quando o abastecimento humano é atendido integralmente pela adutora do rio São Francisco e o reservatório Mirorós sendo responsável apenas pelos usuários do perímetro irrigado e irrigantes a jusante do reservatório. Ressalta-se que por apresentar a alternativa de captação no rio São Francisco, que é um manancial hídrico mais seguro, as decisões de alocação de água do sistema hídrico Mirorós apresentam maior flexibilidade, conforme mencionado por Souza (2020), possibilitando alocar maior quantidade de água para os outros usuários, no entanto o conflito persiste principalmente entre o perímetro irrigado e a liberação de água a jusante.

É importante destacar ainda que municípios como estes representados na área de estudo possuem grande parte das suas atividades econômicas voltada para a agropecuária. Sendo assim, os dois setores de usos, abastecimento humano e irrigação, possuem grande importância, um como recurso natural de sobrevivência e o outro como recurso de subsistência de parte da população. Dessa forma, o uso da água para irrigação tem grande relevância nas discussões e tomadas de decisões sobre o uso da água. 


\section{Análise da distribuição dos benefícios/custos econômicos obtidos pelos usuários}

A Tabela 8 apresenta o custo de escassez associado à alocação nas diferentes alternativas de alocação de água considerando o reservatório Mirorós com o reforço da adutora do rio São Francisco. Também são apresentados o valor da escassez total no período simulado.

Tabela 8 - Benefícios econômicos e custos de escassez das alternativas de alocação de água - Reservatório Mirorós e Adutora do rio São Francisco

\begin{tabular}{|c|c|c|c|c|c|}
\hline \multirow[b]{2}{*}{ Usuário } & \multirow[b]{2}{*}{ Dados econômicos } & \multicolumn{2}{|c|}{ Alternativa 11} & \multicolumn{2}{|c|}{ Alternativa 22} \\
\hline & & $\begin{array}{c}\text { Módulo de } \\
\text { Alocação de } \\
\text { Água (P1) }\end{array}$ & $\begin{array}{l}\text { Módulo de } \\
\text { Análise } \\
\text { Econômica } \\
\text { (E1) }\end{array}$ & $\begin{array}{c}\text { Módulo de Alocação de } \\
\text { Água (P2) }\end{array}$ & $\begin{array}{l}\text { Módulo de Análise } \\
\text { Econômica (E2) }\end{array}$ \\
\hline \multirow{3}{*}{$\begin{array}{c}\text { Abastecimento } \\
\text { humano }\end{array}$} & $\begin{array}{c}\text { Escassez total } \\
\left(\mathrm{hm}^{3}\right)\end{array}$ & 4.941 & 12.273 & 8.620 & 8.620 \\
\hline & \begin{tabular}{|c|} 
Custo de escassez \\
anual médio (R\$ \\
$1.000)$
\end{tabular} & $\mathrm{R} \$ 48.879,40$ & $\mathrm{R} \$ 142.859,10$ & $\mathrm{R} \$ 143.921,90$ & $\mathrm{R} \$ 143.921,70$ \\
\hline & $\begin{array}{c}\text { Custo de escassez } \\
(\%)\end{array}$ & $3,2 \%$ & $9,3 \%$ & $9,3 \%$ & $9,3 \%$ \\
\hline \multirow{3}{*}{$\begin{array}{l}\text { Perímetro } \\
\text { irrigado }\end{array}$} & $\begin{array}{c}\text { Escassez total } \\
\left(\mathrm{hm}^{3}\right)\end{array}$ & 107.590 & 106.224 & 50.037 & 51.456 \\
\hline & $\begin{array}{c}\text { Custo de escassez } \\
\text { anual médio (R\$ } \\
1.000)\end{array}$ & $\mathrm{R} \$ 392.254,60$ & $\mathrm{R} \$ 217.222,00$ & $\mathrm{R} \$ 308.520,10$ & $\mathrm{R} \$ 308.625,90$ \\
\hline & $\begin{array}{c}\text { Custo de escassez } \\
(\%)\end{array}$ & $30,7 \%$ & $17,0 \%$ & $24,2 \%$ & $24,2 \%$ \\
\hline \multirow{3}{*}{$\begin{array}{l}\text { Irrigação a } \\
\text { jusante }\end{array}$} & $\begin{array}{c}\text { Escassez total } \\
\left(\mathrm{hm}^{3}\right)\end{array}$ & 17.266 & 11.248 & 7.805 & 6.044 \\
\hline & $\begin{array}{c}\text { Custo de escassez } \\
\text { anual médio (R\$ } \\
1.000)\end{array}$ & $\mathrm{R} \$ 173.385,49$ & $\mathrm{R} \$ 72.270,60$ & $\mathrm{R} \$ 78.894,70$ & $\mathrm{R} \$ 60.476,30$ \\
\hline & $\begin{array}{c}\text { Custo de escassez } \\
(\%)\end{array}$ & $70,6 \%$ & $29,4 \%$ & $32,1 \%$ & $24,6 \%$ \\
\hline \multirow{3}{*}{ Sistema } & $\begin{array}{c}\text { Escassez total } \\
\left(\mathrm{hm}^{3}\right)\end{array}$ & $129.797,00$ & $129.745,00$ & $66.462,00$ & $66.120,00$ \\
\hline & $\begin{array}{c}\text { Custo de escassez } \\
\text { anual médio (R\$ } \\
1.000) \\
\end{array}$ & $\mathrm{R} \$ 614.519,49$ & $\mathrm{R} \$ 432.351,70$ & $\mathrm{R} \$ 531.336,70$ & $\mathrm{R} \$ 513.023,90$ \\
\hline & $\begin{array}{c}\text { Custo de escassez } \\
(\%)\end{array}$ & $20,1 \%$ & $14,1 \%$ & $17,3 \%$ & $16,7 \%$ \\
\hline
\end{tabular}

Fonte: Próprio autor (2020). Notas: ${ }^{1}$ Vazões afluentes ao reservatório estimadas por próprio autor / ${ }^{2}$ Vazões afluentes ao reservatório estimadas pela ANA.

Como discutido anteriormente, todos os cenários apresentaram déficit no atendimento das demandas, e por isso gerou-se um custo de escassez para cada usuário. Ao analisar os resultados da Alternativa 1, observa-se que, devido à realocação de vazões, quando se utilizou o módulo de análise econômica, o custo de escassez do abastecimento humano teve aumento em aproximadamente $7 \%$, enquanto que o perímetro irrigado e os irrigantes a jusante tiveram um decréscimo no seu custo de escassez, ou seja, seus benefícios médios aumentaram. Os resultados foram mais expressivos para os usuários ribeirinhos a jusante, onde o custo de escassez reduziu de 70\% para 29\%. É importante destacar que quando se considerou o sistema como um todo, o custo de escassez na alternativa econômica reduziu em 6\%, realocando a água de forma mais eficiente do ponto de vista econômico, atingindo o objetivo principal do módulo de análise econômica que é alocar as vazões de forma que ocorra a maximização do benefício total.

Na alternativa 2, observa-se que houve variação apenas para os irrigantes a jusante do reservatório, apresentando uma redução de aproximadamente 8\% no custo de escassez. A realocação de vazões de acordo com os benefícios econômicos conferiu em uma redução do custo de escassez do sistema em $0,6 \%$. As vazões afluentes ao reservatório utilizadas na alternativa 2 propiciaram melhor recuperação do nível 
do reservatório, que, no geral, conseguiu atender as demandas de uma forma mais satisfatória do que na alternativa 1, gerando resultados menos expressivos na análise econômica.

A Tabela 9 apresenta também os custos de escassez considerando o reservatório Mirorós como única fonte de água disponível.

Tabela 9 - Benefícios econômicos e custos de escassez das alternativas de alocação de água - Reservatório Mirorós

\begin{tabular}{|c|c|c|c|c|c|}
\hline \multirow[b]{2}{*}{ Usuário } & \multirow[b]{2}{*}{ Dados econômicos } & \multicolumn{2}{|c|}{ Alternativa 11} & \multicolumn{2}{|c|}{ Alternativa 22} \\
\hline & & $\begin{array}{l}\text { Módulo de } \\
\text { Alocação de } \\
\text { Água (P1) }\end{array}$ & $\begin{array}{l}\text { Módulo de } \\
\text { Análise } \\
\text { Econômica } \\
\text { (E1) }\end{array}$ & $\begin{array}{c}\text { Módulo de Alocação de } \\
\text { Água (P2) }\end{array}$ & $\begin{array}{l}\text { Módulo de Análise } \\
\text { Econômica (E2) }\end{array}$ \\
\hline \multirow{3}{*}{$\begin{array}{l}\text { Abastecimento } \\
\text { humano }\end{array}$} & $\begin{array}{c}\text { Escassez total } \\
\left(\mathrm{hm}^{3}\right)\end{array}$ & 33.165 & 56.003 & 35.531 & 39.157 \\
\hline & $\begin{array}{c}\text { Custo de escassez } \\
\text { anual médio (R\$ } \\
1.000) \\
\end{array}$ & $\mathrm{R} \$ 91.758,20$ & $\mathrm{R} \$ 250.233,20$ & $\mathrm{R} \$ 275.716,90$ & $\mathrm{R} \$ 301.171,50$ \\
\hline & $\begin{array}{c}\text { Custo de escassez } \\
(\%)\end{array}$ & $11 \%$ & $29 \%$ & $32 \%$ & $35 \%$ \\
\hline \multirow{3}{*}{$\begin{array}{l}\text { Perímetro } \\
\text { irrigado }\end{array}$} & $\begin{array}{c}\text { Escassez total } \\
\left(\mathrm{hm}^{3}\right)\end{array}$ & 137.628 & 120.047 & 78.025 & 75.240 \\
\hline & $\begin{array}{c}\text { Custo de escassez } \\
\text { anual médio (R\$ } \\
1.000)\end{array}$ & $\mathrm{R} \$ 804.744,30$ & $\mathrm{R} \$ 276.231,50$ & $\mathrm{R} \$ 474.548,00$ & $\mathrm{R} \$ 407.399,60$ \\
\hline & $\begin{array}{c}\text { Custo de escassez } \\
(\%)\end{array}$ & $63 \%$ & $22 \%$ & $37 \%$ & $32 \%$ \\
\hline \multirow{3}{*}{$\begin{array}{l}\text { Irrigação a } \\
\text { jusante }\end{array}$} & $\begin{array}{l}\text { Escassez total } \\
\left(\mathrm{hm}^{3}\right)\end{array}$ & 18.790 & 13.140 & 10.407 & 9.093 \\
\hline & $\begin{array}{c}\text { Custo de escassez } \\
\text { anual médio (R\$ } \\
1.000)\end{array}$ & $\mathrm{R} \$ 189.931,63$ & $\mathrm{R} \$ 91.350,90$ & $\mathrm{R} \$ 105.192,90$ & $\mathrm{R} \$ 89.935,70$ \\
\hline & $\begin{array}{c}\text { Custo de escassez } \\
(\%)\end{array}$ & $77 \%$ & $37 \%$ & $43 \%$ & $37 \%$ \\
\hline \multirow{3}{*}{ Sistema } & $\begin{array}{l}\text { Escassez total } \\
\left(\mathrm{hm}^{3}\right)\end{array}$ & 189.583 & 189.190 & 123.963 & 123.490 \\
\hline & $\begin{array}{c}\text { Custo de escassez } \\
\text { anual médio (R\$ } \\
1.000)\end{array}$ & $\mathrm{R} \$ 1.086 .434,13$ & $\mathrm{R} \$ 617.815,60$ & $\mathrm{R} \$ 855.457,80$ & $\mathrm{R} \$ 798.506,80$ \\
\hline & $\begin{array}{c}\text { Custo de escassez } \\
(\%)\end{array}$ & $45 \%$ & $26 \%$ & $36 \%$ & $33 \%$ \\
\hline
\end{tabular}

Fonte: Próprio autor (2020). Notas: ${ }^{1}$ Vazões afluentes ao reservatório estimadas por próprio autor/ ${ }^{2}$ Vazões afluentes ao reservatório estimadas pela ANA.

Nessa hipótese, observa-se um crescimento significativo dos custos de escassez, quando comparadas às alternativas com implantação da adutora do rio São Francisco, já que a disponibilidade hídrica reduz significativamente, implicando em maior escassez para os usuários. Nota-se ainda que o custo da escassez do sistema reduziu de $45 \%$ na alternativa P1 para $25 \%$ na alternativa E1, evidenciando que a prioridade dada a determinado usuário pode impor grandes perdas econômicas para os demais usuários e para o sistema como um todo.

Nas regras de operação do sistema hídrico, a eficiência econômica é alcançada ao minimizar o somatório dos custos de escassez de todos os setores, ou seja, a maximização do somatório dos benefícios individuais. Sendo assim, os usuários que apresentarem menor valor agregado à água apresentarão maior escassez hídrica, e isso aconteceu com o abastecimento humano. 0 perímetro irrigado e os irrigantes a jusante, portanto, obtiveram maiores benefícios econômicos na alternativa de alocação utilizando a abordagem hidroeconômica.

Analisando as alternativas P2 e E2, observa-se o mesmo comportamento obtido nas alternativas P1 e E1, porém com variações mais sutis. Vale lembrar que nas alternativas 2 , a disponibilidade hídrica é maior.

Embora a minimização do custo de escassez do sistema ocorra quando menor quantidade de água é alocada para o abastecimento humano, é importante ressaltar que quando esse uso não possui outro 
manancial para captação, alocar a água considerando apenas a maximização dos benefícios econômicos pode contradizer o fundamento da Lei das Águas, que define o consumo humano como uso prioritário em casos de escassez hídrica, podendo ser considerada uma fragilidade da implementação isolada da abordagem hidroeconômica. Sendo assim, é importante avaliar a viabilidade de aplicação da metodologia de acordo com o estudo de caso, como será mostrado no item a seguir.

\section{Contribuições para o SINGREH}

Através da inserção da abordagem hidroeconômica no processo de alocação negociada de água, busca-se simular o comportamento do sistema hídrico, quantificar o valor da água e perdas econômicas relacionadas às restrições de uso, e auxiliar as tomadas de decisões na alocação de água em reservatórios que apresentem escassez hídrica.

Existem alguns mecanismos de alocação de água, sendo o mais utilizado no Brasil a "Administração Pública da Água", que consiste na distribuição, por parte do poder público, de cotas de uso da água, as denominadas outorgas de uso. Para Ambrosio \& Formiga-Johnsson (2018), a outorga é um importante mecanismo de alocação a longo prazo, porém insuficiente em crises hídricas, quando é necessária sua revisão a curto prazo. Dessa forma, a alocação negociada de água torna-se um instrumento mais eficiente na resolução de conflitos de uso da água.

A alocação negociada de água é um mecanismo que tem sido adotado em períodos de escassez hídrica, caracterizado pela construção de diálogo entre o Poder Público e os usuários. A alocação negociada tem se fortalecido na gestão de recursos hídricos, principalmente, quando existe participação direta e efetiva dos usuários (Spolidorio, 2017). A negociação da alocação de água tem como ponto de partida das discussões o comportamento hidrológico do manancial.

$\mathrm{Na}$ alocação negociada em reservatórios realizada pela Cogerh realiza-se a simulação do esvaziamento do reservatório para diversas retiradas, a fim de estabelecer os cenários de liberação de água para os usuários em um determinado período. Os cenários são apresentados e servem como base para a negociação da alocação de água junto aos usuários nas reuniões de planejamento da operação do reservatório (Pinheiro et al., 2011). Metodologia similar é adotada pela ANA, sendo os cenários propostos e suas respectivas curvas de esvaziamento do reservatório apresentados aos usuários nas reuniões de alocação de água. Os atores envolvidos apresentam decisões baseadas nos dados hidrológicos apresentados e em seus interesses e, geralmente, não tomam conhecimento dos custos ou benefícios econômicos associados às regras de alocação de água.

Com base na metodologia apresentada nesse artigo, é possível comparar os cenários de restrições de uso com base nos benefícios econômicos, e assim mensurar os custos econômicos para cada usuário, e para o sistema, de acordo com as políticas de uso adotadas.

Através dos benefícios marginais, os gestores de recursos hídricos buscam compreender o comportamento dos usuários, com o objetivo de garantir o equilíbrio entre a oferta e demanda da água entre os diversos setores usuários. Os gestores ou entidades reguladoras podem utilizar o benefício econômico como base complementar para decisão de oferta de água para os usuários. Além disso, os usuários, ao tomar conhecimento dos custos de escassez de água, podem ser induzidos ao uso racional de água, e à maximização da sua produtividade por $\mathrm{m}^{3}$ captado, no caso dos usuários agrícolas (Livele \& Silveira, 2015). Silva et al. (2017) destacam que grandes déficits de água apresentam custo social e econômico elevados, que podem ser mitigados através da utilização dos instrumentos econômicos.

No entanto, considerar apenas a maximização do benefício econômico não torna a alocação ideal. Brigagão \& Cordeiro Netto (2007) ressaltam a complexidade do processo de alocação de água e a importância de a análise econômica estar associada à outras análises, visto que a alocação, além dos aspectos econômicos, envolve aspectos legais, institucionais, sociais, técnicos e ambientais.

Através da associação entre a alocação negociada e a análise hidroeconômica, é possível buscar um equilíbrio entre eficiência econômica e social, relacionando os instrumentos de controle e os instrumentos econômicos, e considerando as características ambientais. Não se espera que a abordagem hidroeconômica substitua a alocação negociada da água praticada nos sistemas hídricos, mas que seja uma abordagem complementar ao processo, sendo mais um subsídio para as tomadas de decisão dos gestores e usuários.

Posto isso, propõe-se a inserção da abordagem hidroeconômica na alocação negociada de água. A Figura 11 apresenta o fluxograma da metodologia proposta. A metodologia divide-se em 6 (seis) etapas. 


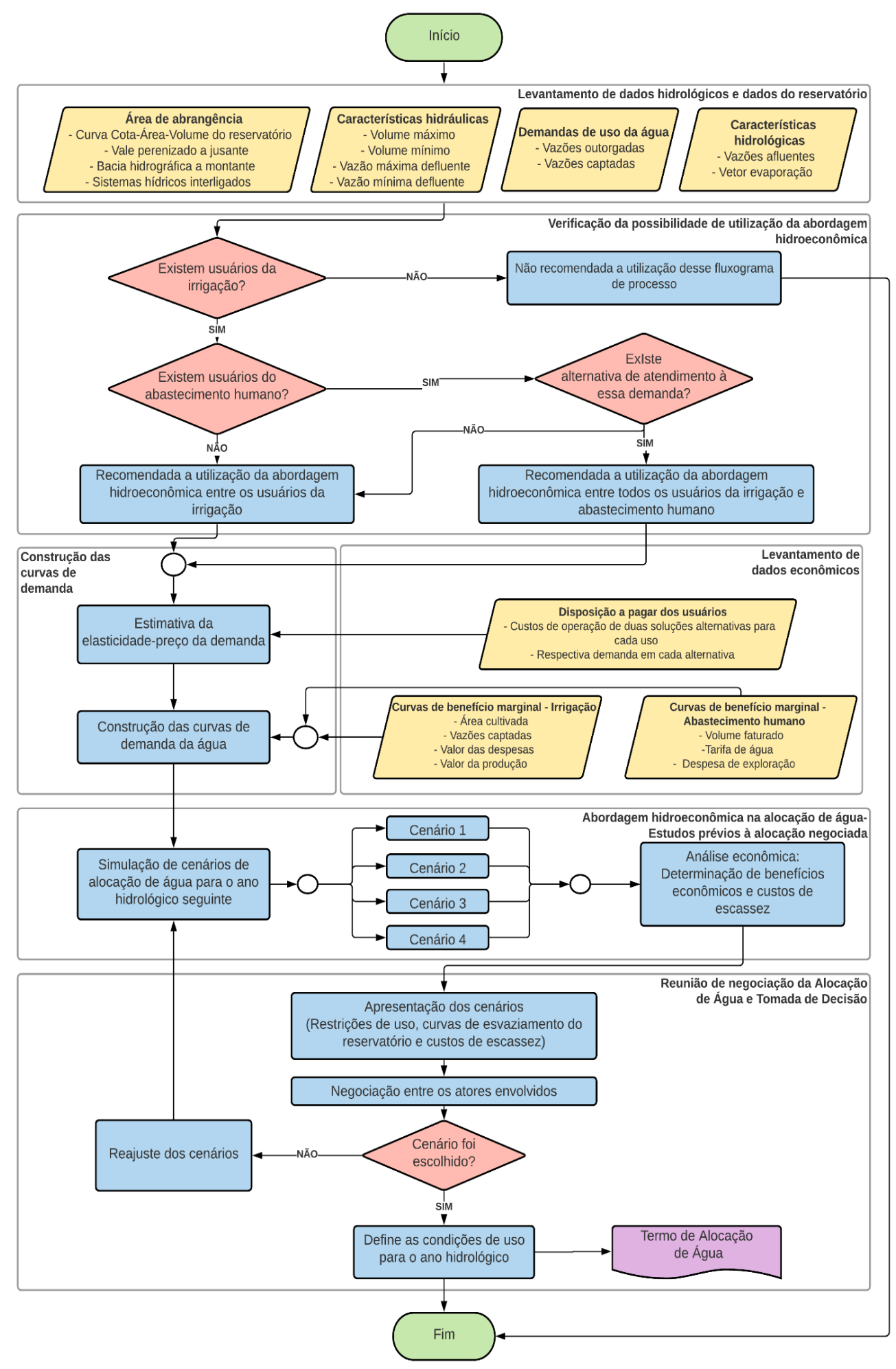

Figura 11 - Procedimentos para a implementação da abordagem hidroeconômica na alocação negociada de água em reservatórios envolvendo o uso de irrigação. Fonte: Próprio autor (2020).

A primeira etapa consiste no levantamento de dados hidrológicos e dados do reservatório, que deve contemplar a área de abrangência do reservatório, as características hidráulicas do reservatório, as demandas de uso da água e as características hidrológicas da área de estudo. Posteriormente, deve-se verificar se é recomendado utilizar a abordagem hidroeconômica, com base nas demandas de uso existentes. Primeiramente, verifica-se a existência de usuários da irrigação, e tem-se duas opções: caso a resposta seja negativa, não se recomenda utilizar a abordagem hidroeconômica proposta, isso porque a mesma está 
direcionada para alocação de água em reservatórios que apresentem o uso da irrigação, e assim, encerra-se o processo. Sendouma respsota positiva, dá-se continuidade ao processo com a segunda verificação, na qual buscase responder sobre a existência de usuário do abastecimento humano. Caso negativo, recomenda-se a utilização da abordagem hidroeconômica para a alocação de água entre os usuários da irrigação. Caso exista usuário do abastecimento humano, é necessário verificar se o usuário é atendido apenas pelo reservatório em questão ou se existe a possibilidade de captação em um manancial alternativo que ofereça segurança hídrica. Existindo outro manancial para atender a essa demanda, recomenda-se a utilização da abordagem hidroeconômica na alocação de água entre todos os usuários, sejam eles do setor agrícola ou do setor do abastecimento humano. Caso o reservatório em estudo seja o único manancial de captação, esse uso deve ser atendido de acordo com as prioridades, e a análise hidroeconômica pode ser implementada na alocação entre os usuários da irrigação.Em seguida, é realizado o levantamento de dados econômicos dos usuários e a construção das curvas de demanda (etapas 3 e 4). Existem diversos métodos para a estimativa dessas curvas. Foi testada a utilização do Método de Expansão do Ponto, no entanto, o operador do modelo pode utilizar o método que for mais adequado à sua área de estudo e aos dados disponíveis. A etapa 5 compreende a análise econômica na alocação de água, por meio da simulação dos cenários de alocação de água. Durante o processo de alocação negociada, a ANA realiza a simulação de três cenários de atendimento dos usos para o ano hidrológico seguinte. Considerando essa metodologia, propõe-se o acréscimo de um cenário que tenha como objetivo a maximização dos benefícios totais. Além disso, propõe-se a análise econômica dos quatro cenários simulados, com o objetivo de estimar o benefício anual médio e o custo de escassez de cada cenário de alocação.A última etapa consiste na reunião da alocação de água. Durante a reunião, os cenários de vazões alocadas devem ser apresentados juntamente com a curva de esvaziamento do reservatório, seus benefícios econômicos e custos de escassez. Ao realizar a análise econômica dos cenários de alocação de água, permite-se ao usuário avaliar o impacto econômico dos cenários de alocação de água, auxiliando sua tomada de decisão. Nesse sentido, os gestores têm o valor econômico como base complementar para a decisão da oferta de água entre os usuários.

\section{CONSIDERAÇÕES FINAIS}

De acordo com a Política Nacional de Recursos Hídricos, a água é um recurso natural limitado e dotado de valor econômico. A partir do momento em que a água se torna escassa, ocasionando conflitos entre os usuários, as demandas precisam ser consideradas como demandas variáveis. Na economia, a demanda de água varia com o seu preço. 0 gerenciamento da demanda a partir da implementação de mecanismos econômicos pode tornar o uso do recurso mais eficiente. Sendo assim, diversos autores defendem a análise dos valores econômicos na alocação de água, resultando em uma análise hidroeconômica. No entanto, nos atuais processos de planejamento e gestão das águas, geralmente se considera a demanda de água como um valor fixo.

No sentido de minimizar estas falhas, o objetivo geral dessa pesquisa foi estabelecer procedimentos para a implementação da abordagem hidroeconômica no processo de alocação de água em reservatórios que apresentam conflitos de uso envolvendo a irrigação. A área de estudo escolhida foi o reservatório Mirorós, que apresenta um regime hidrológico crítico e apresentam conflitos de uso da água envolvendo três principais usuários: o abastecimento humano, o perímetro irrigado de Mirorós e os irrigantes ribeirinhos a jusante do reservatório.

A abordagem hidroeconômica buscou maximizar o somatório dos benefícios econômicos de cada usuário. Sendo assim, maior quantidade de água foi alocada para os usuários que apresentaram maior valor agregado à água, que nesse caso foram os irrigantes ribeirinhos a jusante e o perímetro irrigado. Observou-se melhorias mais significativas nos indicadores de atendimento da demanda dos irrigantes ribeirinhos a jusante do reservatório.

A partir da estimativa dos benefícios econômicos da alocação de água, concluiu-se que as prioridades de uso da água estabelecidas para o abastecimento humano geraram elevados custos de escassez para os usuários da irrigação e para o sistema como um todo, tornando a alocação de água menos eficiente do ponto de vista econômico. Contudo, considerando que o abastecimento humano é um uso essencial e prioritário em casos de escassez hídrica, fundamentado pela Política Nacional de Recursos Hídricos, considerou-se que a recomendação de utilizar a abordagem hidroeconômica nesse caso é aceita quando o usuário do abastecimento humano possuir um manancial alternativo seguro para captação de água, como é o caso do SIAA Irecê, que além de possuir a outorga de captação no reservatório Mirorós, dispõe da captação de água no rio São Francisco para atendimento de suas demandas de forma integral.

Observa-se que nem sempre as prioridades de uso da água estabelecidas para um sistema hídrico refletem em uma solução economicamente eficiente, visto que os benefícios adquiridos por determinados usuários podem impor elevados custos aos demais. No entanto, destaca-se que não é 
interessante considerar apenas a maximização do benefício econômico na alocação, sendo necessário considerar diversos aspectos, como por exemplo as prioridades de uso da água.

Portanto, o presente artigo oferece uma contribuição metodológica para a alocação de água, através da inserção da abordagem hidroeconômica na alocação negociada. A metodologia objetiva o uso integrado e racional da água e busca atender aos fundamentos da Política Nacional de Recursos Hídricos, através da gestão participativa e descentralizada dos recursos hídricos e do reconhecimento da água como recurso natural limitado e dotado de valor econômico.

Vale destacar que mesmo atingindo o objetivo proposto, no decorrer da pesquisa, foram encontradas algumas limitações, que precisam ser relatadas com o objetivo de possibilitar melhorias na análise:

- a metodologia analisou apenas os usuários de irrigação e abastecimento humano, sendo necessários estudos envolvendo outros usos da água, visto que os conflitos se estendem a múltiplos usos, tais como geração de energia hidrelétrica, piscicultura, depuração de efluentes, entre outros;

- $\quad$ incerteza dos dados utilizados na construção das curvas de benefício marginal, necessitando de análise econométrica mais aprofundada para estimativa adequada dos benefícios marginais dos usuários;

- $\quad$ utilização da elasticidade-preço da demanda constante, visto que esse parâmetro varia com o ponto de operação utilizado para sua determinação, conferindo assim imprecisão do valor da água em pontos distantes do ponto utilizado como base para a sua estimativa;

- $\quad$ o efeito da sazonalidade nas demandas de água, aspecto não considerado nessa pesquisa, esse efeito está relacionado principalmente aos usuários de irrigação, visto que as necessidades hídricas das culturas variam significativamente com o estágio de desenvolvimento e com as condições climáticas (período seco ou chuvoso);

- $\quad$ benefícios econômicos da proteção ambiental não foram considerados na metodologia, sendo essa variável considerada apenas por restrições hidrológicas. Dessa forma recomenda-se estimar curvas de benefício marginal da vazão ambiental, buscando incorporar os benefícios e custos de escassez da proteção ambiental ao processo de alocação de água;

- $\quad$ as prioridades de uso da água destinada aos usuários do abastecimento humano que não foram consideradas na estimativa do benefício marginal, sendo a prioridade do usuário considerada apenas na viabilidade da aplicação da metodologia. Sendo assim recomenda-se aprofundar a estimativa das curvas de demanda desse usuário, buscando internalizar as externalidades associadas ao não acesso à água para consumo humano. Esse efeito pode ser mitigado também a partir da utilização de uma abordagem multicritério para a alocação de água, considerando as prioridades de uso da água em conjunto com os demais aspectos da análise hidroeconômica.

Diante do exposto, as limitações observadas podem ser consideradas como oportunidades para futuras pesquisas acerca do tema.

\section{AGRADECIMENTOS}

O presente trabalho foi realizado com apoio da Coordenação de Aperfeiçoamento de Pessoal Nível Superior - Brasil (CAPES) - Código de Financiamento 001, agradeço também ao Programa de Mestrado Profissional em Rede Nacional em Gestão e Regulação de Recursos Hídricos - ProfÁgua, Projeto CAPES/ANA AUXPE №. 2717/2015, pelo apoio técnico científico aportado.

\section{REFERÊNCIAS}

Agência Nacional de Águas - ANA. (2017a). Reservatórios do semiárido brasileiro: hidrologia, balanço hídrico e operação: relatório síntese (88 p.). Brasília. Recuperado em 11 de fevereiro de 2020, de https://metadados.snirh.gov.br/geonetwork/srv/api/records/ccc25b76-f711-41ea-a79ec8d30c287e53/attachments/Reservatrios_do_semiarido_brasileiro_hidrologia,_balano_hdrico_e_operao.pdf

Agência Nacional de Águas - ANA. (2017b). Nota técnica nํ13/2017/COMAR/SER: marco regulatório estabelecendo condições de uso dos recursos hídricos no sistema hídrico Mirorós, no Estado da Bahia. Brasília. Recuperado em 20 de janeiro de 2020, de https://www.gov.br/ana/pt-br/todos-os-documentos-do-portal/documentossre/resolucoes-e-normativos/regras-especiais-de-uso-da-agua/marcosregulatorios/nt_13_2017_comar_sre.pdf

Agência Nacional de Águas - ANA. (2020a). Sistema de Acompanhamento de Reservatório (SAR): dados históricos Reservatório Mirorós (Manoel Novais). Brasília. Recuperado em 15 de junho de 2020, de https://www.ana.gov.br/sar0/MedicaoSin 
Agência Nacional de Águas - ANA. (2020b). Vazões afluentes ao reservatório Mirorós. Coordenação de Estudos Hidrológicos. Mensagem recebida por <mariane.ravanello@ana.gov.br> em 22 jan. 2020.

Agência Peixe Vivo - AGP. (2018). Plano municipal de saneamento básico do município de Xique Xique. Produto 3: prognóstico, programas, projetos e ações. Recuperado em 10 de outubro de 2020, de https://2017.cbhsaofrancisco.org.br/2017//box/uploads/2018/01/PLANO-DE-TRABALHO-XIQUE-XIQUE.pdf

Agência Reguladora de Saneamento Básico do Estado da Bahia - AGERSA. (2016). Relatório de fiscalização: sistemas de abastecimento de água e esgotamento sanitário da Adutora do Feijão. Salvador. Recuperado em 18 de janeiro de 2020, de www.agersa.ba.gov.br/wp-content/uploads/2013/01/relatorio-irece.pdf

Ambrosio, L. L., \& Formiga-Johnsson, R. M. (2018). Alocação de água nas bacias dos rios Paraíba do Sul e Guandu. Boletim do Observatório Ambiental Alberto Ribeiro Lamego, 12(2), 215-233. Recuperado em 2 de novembro de 2020, de https://essentiaeditora.iff.edu.br/index.php/boletim/article/view/11751

Bahia. Secretaria de Infraestrutura Hídrica e Saneamento. (2016) Embasa 45 anos fazendo história no saneamento da Bahia. Salvador: SIHS. Recuperado em 21 de fevereiro de 2020, de https://www.embasa.ba.gov.br/images/documents/2083/livro_45anos_embasa_7out2016_arte_web_2abr20 19_bx.pdf

Basto, I. D. R. G., Fontes, A. S., \& Medeiros, Y. D. P. (2020). Effects of an outflow regime adoption of the São Francisco River reservoir system to meet water demands for multiple uses. Revista Brasileira de Recursos Hídricos, 25, e31. http://dx.doi.org/10.1590/2318-0331.252020190110

Brigagão, E. N., \& Cordeiro Netto, O. M. C. (2007). Proposta para integração de análise econômica e finaceira ao SAD Acquanet. In Anais do 17ํㅗㅇimpósio Brasileiro de Recursos Hídricos. São Paulo. Recuperado em 18 de julho de 2021, de https://abrh.s3.sa-east1.amazonaws.com/Sumarios/19/59a27d4f8dfd369137b97399a1ea35be_85977ac15d7b9881a15dd69e5321 4745.pdf

Carrera-Fernandez, J., \& Garrido, R. (2002). Economia dos recursos hídricos (458 p.). Salvador: Edufba.

Companhia de Desenvolvimento do Vale do São Francisco e do Parnaíba - CODEVASF. (2013). Edital no 59/2013. Execução das obras e serviços necessários para perfuração e instalação de 241 poços tubulares novos e instalação de 78 poços tubulares existentes, em municípios sob a jurisdição da $2^{a}$ e da $6^{\underline{a}}$ Superintendência Regional da Codevasf, no Estado da Bahia.

Companhia de Desenvolvimento do Vale do São Francisco e do Parnaíba - CODEVASF. (2019). Dados de produção do Perímetro Irrigado de Mirorós (safra 2019). Mensagem recebida por <urbirajara.filho@codevasf.gov.br>em 04 fev. 2020.

Companhia de Energia Elétrica da Bahia - COELBA. (2020). Tabela de tarifas de energia elétrica. Recuperado em 14 de outubro de 2020, de https://servicos.coelba.com.br/residencialrural/Pages/Baixa\%20Tens\%C3\%A3o/tarifas-grupo-b.aspx

Dalcin, A. P., \& Marques, G. F. (2019). Simulação da qualidade da água para suporte em modelos de otimização para planejamento e gestão de recursos hídricos. Revista de Gestão de Água da América Latina, 16, e15. https://dx.doi.org/10.21168/rega.v16e15

Distrito de Irrigação do Perímetro Irrigado de Mirorós - DIPIM. (2019). Relatório de Captação de água (Maio/2017 a Abril/2019). Mensagem recebida por <escritoriodipim@hotmail.com> em 20 maio 2020.

Fernandez y Fernandez, M., Ayrimoraes Soares, S. R., \& Nunes, C. M. (2007). Estimativas de preços de implantação, operação e manutenção de unidades e de sistemas de adução, de bombeamento e de tratamento de água. Revista AIDIS de Ingeniería y Ciencias Ambientales: Investigación, Desarrollo y Práctica, 1(3), 1-14. Recuperado em 10 de setembro de 2020, de http://revistas.unam.mx/index.php/aidis/article/view/14423/13759

Garrido, R. J. S. (2018). Contribuições à cobrança pelo uso da água no Brasil: Abordagem econômica e avaliação de preços ótimos vis-à-vis preços praticados na bacia do rio Paraíba do Sul (Tese de doutorado). Faculdade de Economia, Administração e Contabilidade, Universidade de Brasília, Brasília. Recuperado em 5 de setembro de 2020 , de https://repositorio.unb.br/bitstream/10482/32163/1/2018_RaymundoJos\%C3\%A9SantosGarrido.pdf

Harou, J. J., Pulido-Velazquez, M., Rosenberg, D. E., Medellín-Azuara, J., Lund, J. R., \& Howitt, R. E. (2009). Hydro-economic models: Concepts, design, applications, and future prospects. Journal of Hydrology, 375(3-4), 627-643. http://dx.doi.org/10.1016/j.jhydrol.2009.06.037

Hashimoto, T., Stedinger, J., \& Loucks, D. P. (1982). Reliability, resilience and vulnerability criteria for water resource system performance evaluation. Water Resources Research, 18(1), 14-20. http://dx.doi.org/10.1029/WR018i001p00014 
Instituto Brasileiro de Geografia e Estatística - IBGE. (2017a). Censo agropecuário: resultados definitivos. Recuperado em 22 de janeiro de 2020, de https://sidra.ibge.gov.br/pesquisa/censoagropecuario/censo-agropecuario-2017/

Instituto Brasileiro de Geografia e Estatística - IBGE. (2017b). Produção agrícola municipal: tabelas. Recuperado em 22 de janeiro de 2020, de https://sidra.ibge.gov.br/pesquisa/pam/tabelas

Instituto do Meio Ambiente e Recursos Hídricos - INEMA. (2019). Dados de usuários dos rios Verde e Jacaré. Mensagem enviada por <nout-sei@inema.ba.gov.br> em 12 nov. 2019.

Livele, V. A., \& Silveira, A. L. L. (2015). Impactos econômicos da capacidade e regra operacional do sistema hídrico da parte moçambicana da bacia do rio Limpopo para satisfação das atuais e futuras demandas de água na agricultura irrigada. Revista de Gestão de Água da América Latina, 12(1), 63-76. http://dx.doi.org/10.21168/rega.v12n1.p63-76

Loucks, D. P. (1997). Quantifying trends in system sustainability. Hydrological Sciences Journal, 42(4), 513-530. http://dx.doi.org/10.1080/02626669709492051

MacEwan, D., Cayar, M., Taghavi, A., Mitchell, D., Hatchett, S., \& Howitt, R. (2017). Hydroeconomic modeling of sustainable groundwater management. Water Resources Research, 53(3), 2384-2403. http://dx.doi.org/10.1002/2016WR019639

Mattiuzi, C. D. P., Marques, G. F., Medellin-Azuara, J., \& Dalcin, A. P. (2020). The economic value of water in crop productions and policy implications in southern Brazil. Water Management, 1-26. http://dx.doi.org/10.1680/jwama.19.00084

Moraes, M. M. G. A., Albuquerque Filho, B. E. M., Amorim Filho, C. A. G., Silva, G. S. (2014). SSD espacial para la gestión óptima de sistemas de recursos hídricos incorporando modelos hidroeconómicos. In Metodologias y experiencias prácticas. Recuperado em 20 de janeiro de 2020, de https://www.researchgate.net/publication/265508290

Moraes, M. M. G. A., Biweald, A., Carneiro, A. C. G., da Silva, G. N. S., Popp, A., \& Lotze-Campen, H. (2018). The impact of global change on economic values of water for Public Irrigation Schemes at the São Francisco River Basin in Brazil. Regional Environmental Change, 18(7), 1943-1955. http://dx.doi.org/10.1007/s10113-018-1291-0

Organização para a Cooperação e o Desenvolvimento Econômico - OCDE. (2015). Governança dos recursos hídricos no Brasil. Paris: OECD Plubishing. https://doi.org/10.1787/9789264238169-pt

Pinheiro, M. I. T., Campos, J. N. B., \& Studart, T. M. (2011). Conflitos por águas alocação negociada: o caso do vale dos Carás no Ceará. Revista de Administração Pública, 45(6), 1655-1672. http://dx.doi.org/10.1590/S0034-76122011000600003

Preziosi, E., Del Bon, A., Romano, E., Petrangeli, A. B., \& Casadei, S. (2013). Vulnerability to drought of a complex water supply system: the Upper Tiber Basin Case Study (Central Italy). Water Resources Management, 27(13), 4655-4678. http://dx.doi.org/10.1007/s11269-013-0434-9

Reynaud, A., \& Romano, G. (2018). Advances in the economic analysis of residential water use: an introduction. Water, 10(9), 1162. http://dx.doi.org/10.3390/w10091162

Rocha, O. P. (2020). Reunião [jul. 2020]. Alocação de Água do reservatório Mirorós - 2020/2021. ANA. Recuperado em 30 de outubro de 2020, de https://www.youtube.com/watch?v=pZmlWTkFK$s \& t=2548 s$

Silva, A. M. O., Souza Filho, F., \& Aquino, S. H. S. (2017).Avaliação do risco da alocação de água em período de escassez hídrica: o caso do Sistema Jaguaribe-Metropolitano. Engenharia Sanitaria e Ambiental, 22(4), 749-760. http://dx.doi.org/10.1590/s1413-41522017161303

Silva, G. N. S. S., Figueiredo, L. E. N., \& Moraes, M. M. G. A. (2015). Curvas de demanda pelos recursos hídricos dos principais usos consuntivos no submédio da Bacia do rio São Francisco. Brazilian Journal of Environmental Sciences, (36), 45-59. http://dx.doi.org/10.5327/Z2176-947820151004

Silva, G. N. S., \& Moraes, M. M. A. (2021). Decision support for the (inter-)basin management of water resources using integrated hydro-economic modeling. Hydrology, 8(1), 42. http://dx.doi.org/10.3390/hydrology8010042

Silva, G. N. S., \& Moraes, M. M. G. A. (2018). Economic water management decisions: trade-offs between conflicting objectives in the sub-middle region of the São Francisco watershed. Regional Environmental Change, 18(7), 1957-1967. http://dx.doi.org/10.1007/s10113-018-1319-5

Sistema Nacional de Informação sobre Saneamento - SNIS. (2018). Série histórica: água e esgotos. Recuperado em 23 de maio de 2020, de http://app4.mdr.gov.br/serieHistorica 
Souza, W. G. (2020). Reunião alocação de água em sistemas hídricos locais: metodologia e aplicação. ANA. Recuperado em 28 de outubro de 2020, de https://www.youtube.com/watch?v=llljwd514UA\&t=3170s

Spolidorio, P. C. M. (2017). A alocação negociada de água como estratégia de regulação responsiva. Revista de Direito Setorial e Regulatório, 3(1), 183-198.

Tropical Poços. (2020). Custos para implantação de poços na região do município de Irecê. Mensagem recebida por Whatsapp em 19 out. 2020. 15:50.

Vichete, W. D., \& Mello Júnior, A. V. (2021). Análise de decisão hidroeconômica na alocação de água para abastecimento urbano em sistemas complexos de reservatório. Revista DAE, 69(230), 108-126. http://dx.doi.org/10.36659/dae.2021.035

\section{Contribuições dos autores:}

Emanoella Rodrigues Ribeiro de Oliveira: desenvolvimento da pesquisa a partir de seu projeto no Mestrado Profissional em Gestão e Regulação de Recursos Hídricos - ProfÁgua. Simulação no modelo, análise de dados e resultados.

Andrea Sousa Fontes: definição da metodologia de estudo, suporte na análise dos resultados e supervisão da pesquisa.

Raymundo José Santos Garrido: suporte na aplicação da metodologia e análise dos resultados.

William Dantas Vichete: suporte na aplicação da metodologia.

Yvonilde Dantas Pinto Medeiros: suporte nas análises dos resultados.

Paulo Romero Guimarães Serrano de Andrade: co-supervisão da pesquisa. 